\title{
Northward ITCZ shift drives reduced ENSO activity in the Mid-Pliocene Warm Period
}

Gabriel Pontes ( $\sim$ gabrielpontes@usp.br)

University of São Paulo https://orcid.org/0000-0003-4397-4238

Andrea Taschetto

UNSW https://orcid.org/0000-0001-6020-1603

Alex Sen Gupta

The University of New South Wales https://orcid.org/0000-0001-5226-871X

\section{Agus Santoso}

The University of New South Wales https://orcid.org/0000-0001-7749-8124

\section{llana Wainer}

Instituto Oceanogr\&\#x00E1 https://orcid.org/0000-0003-3784-623X

\section{Alan Haywood}

University of Leeds

\section{Wing-Le Chan}

The University of Tokyo https://orcid.org/0000-0002-5646-6104

\section{Ayako Abe-Ouchi}

University of Tokyo https://orcid.org/0000-0003-1745-5952

\section{Christian Stepanek}

Alfred Wegener Institute Helmholtz Centre for Polar and Marine Research https://orcid.org/0000-00023912-6271

\section{Gerrit Lohmann}

Alfred Wegener Institute https://orcid.org/0000-0003-2089-733X

\section{Stephen Hunter}

University of Leeds https://orcid.org/0000-0002-4593-6238

Julia Tindall

University of Leeds https://orcid.org/0000-0002-2360-5761

\section{Mark Chandler}

Columbia University-NASA/GISS

\section{Linda Sohl}

Columbia University

\section{Dick Peltier}

University of Toronto

\section{Deepak Chandan}

University of Toronto 


\section{Youichi Kamae}

University of Tsukuba

\section{Kerim Nisancioglu}

University of Bergen

\section{Zhongshi Zhang}

China University of Geosciences https://orcid.org/0000-0002-2354-1622

\section{Camille Contoux}

Laboratoire des Sciences du Climat et de l'Environnement, LSCE/IPSL

\section{Ning Tan}

Key Laboratory of Cenozoic Geology and Environment, Institute of Geology and Geophysics, Chinese Academy of Sciences,

\section{Qiong Zhang}

Stockholm University https://orcid.org/0000-0002-9137-2883

\section{Bette Otto-Bliesner}

National Center for Atmospheric Research https://orcid.org/0000-0003-1911-1598

\section{Esther Brady}

National Center for Atmospheric Research

\section{Ran Feng}

University of Connecticut

\section{Anna von der Heydt}

Utrecht University

\section{Michiel Baatsen}

University of Utrecht https://orcid.org/0000-0002-0123-7005

\section{Arthur Oldemann}

Utrecht University

\section{Article}

Keywords: El Niño Southern Oscillation (ENSO), ocean science, Mid-Pliocene Warm Period

Posted Date: June 22nd, 2021

DOl: https://doi.org/10.21203/rs.3.rs-402220/v1

License: (c) (1) This work is licensed under a Creative Commons Attribution 4.0 International License. Read Full License

Version of Record: A version of this preprint was published at Nature Geoscience on August 11th, 2022. See the published version at https://doi.org/10.1038/s41561-022-00999-y. 
Gabriel M. Pontes $^{* 1}$, Andréa S. Taschetto ${ }^{2,3}$, Alex Sen Gupta ${ }^{2,3}$, Agus Santoso ${ }^{2,3,4}$, Ilana Wainer $^{1}$, Alan Haywood ${ }^{5}$, Wing-Le Chan ${ }^{6}$, Ayako Abe-Ouchi ${ }^{6}$, Christian Stepanek ${ }^{7}$, Gerrit Lohman ${ }^{7}$, Stephen Hunter ${ }^{5}$, Julia C. Tindall ${ }^{5}$, Mark A. Chandler ${ }^{8}$, Linda E. Sohl ${ }^{8}$, W. Richard Peltier ${ }^{9}$, Deepak Chandan ${ }^{9}$, Youichi Kamae ${ }^{10}$, Kerim H. Nisancioglu ${ }^{11}$, Zhongshi Zhang ${ }^{11}$, Camille Contoux ${ }^{12}$, Ning Tan ${ }^{12,13}$, Qiong Zhang ${ }^{14}$, Bette OttoBliesner ${ }^{15}$, Esther C. Brady ${ }^{15}$, Ran Feng ${ }^{16}$, Anna S. von der Heydt ${ }^{17}$, Michiel L. J. Baatsen $^{17}$, Arthur M. Oldeman ${ }^{17}$

*Corresponding author: Gabriel M. Pontes (gabrielpontes@usp.br)

$11{ }^{1}$ Oceanographic Institute, University of São Paulo, São Paulo, Brazil

$12{ }^{2}$ Climate Change Research Centre, The University of New South Wales, Australia

$13{ }^{3}$ ARC Centre of Excellence for Climate Extremes, The University of New South Wales, 14 Australia

$15{ }^{4}$ Centre for Southern Hemisphere Oceans Research, CSIRO Oceans and Atmosphere, 16 Hobart, Tasmania, Australia

$17{ }^{5}$ School of Earth and Environment, University of Leeds, Leeds, UK

$18{ }^{6}$ Centre for Earth System Dynamics, Atmosphere and Ocean Research Institute, University 19 of Tokyo, Japan

$20{ }^{7}$ Alfred Wegener Institute, Helmholtz Centre for Polar and Marine Research, Bremerhaven, 21 Germany

$22{ }^{8}$ NASA/GISS, Columbia CCSR, Columbia University, New York, NY 10025, USA

$23{ }^{9}$ Department of Physics, University of Toronto, Toronto, Canada

$24{ }^{10}$ Faculty of Life and Environmental Sciences, University of Tsukuba, Tsukuba, Japan

$25{ }^{11}$ NORCE Norwegian Research Centre, Bjerknes Centre for Climate Research, 5007 26 Bergen, Norway

$27{ }^{12}$ Laboratoire des Sciences du Climat et de l'Environnement, LSCE/IPSL, CEA-CNRS28 UVSQ Université Paris-Saclay, 91191 Gif-sur-Yvette, France

$29{ }^{13}$ Key Laboratory of Cenozoic Geology and Environment, Institute of Geology and 30 Geophysics, Chinese Academy of Sciences, Beijing 100029, China

$31{ }^{14}$ Department of Physical Geography and Bolin Centre for Climate Research, Stockholm 32 University, Stockholm, 10691, Sweden

$33{ }^{15}$ National Center for Atmospheric Research, Boulder, USA

$34{ }^{16}$ Department of Geosciences, College of Liberal Arts and Sciences, University of 35 Connecticut, Storrs, CT 06033, USA

$36{ }^{17}$ Institute for Marine and Atmospheric research Utrecht (IMAU), Department of Physics, 37 Utrecht University, Utrecht, 3584 CS, the Netherlands 
39 The El Niño Southern Oscillation (ENSO) is the strongest pattern of year-to-year

40 climate variability found in the equatorial Pacific Ocean with global impacts.

41 However, it is not fully understood how ENSO responds to different warming

42 scenarios. In the warmer climate $(\sim 2-3 K)$ of the mid-Pliocene Warm Period ( $\sim 3$ Ma

43 BP), models consistently suggest a weakening of ENSO variability, with a mean

44 reduction of $25 \%( \pm \mathbf{1 6 \%})$. We show that a near unanimous weakening of ENSO

45 across models cannot be fully explained simply by mean state changes in the

46 equatorial Pacific Ocean. Instead, robust off-equatorial mean state changes in the

47 mid-Pliocene are not favourable for ENSO activity. A northward displacement of the

48 Pacific Inter-Tropical Convergence Zone (ITCZ) is found to be significantly linked to

49 the ENSO weakening across models. This is accompanied by increased south-easterly

50 trade winds in the western Pacific and an intensified South Pacific Subtropical High,

51 which are consistent with suppressed activity of processes that initiate ENSO. Our

52 results provide a constraint to past and future changes to ENSO associated with the

53 climatological ITCZ position.

55 ENSO warm (El Niño) and cold (La Niña) events cause significant changes in weather

56 patterns and ocean circulations, impacting on agriculture, fisheries, coral bleaching,

57 cyclogenesis, among a host of other impacts ${ }^{1}$. Given its pronounced social and economic

58 impacts and potential predictability of a few seasons in advance, ENSO has been a subject

59 of intense investigation ${ }^{2}$. Whether and how ENSO changes in response to greenhouse and

60 other external forcings may be studied by investigating past, present, and future climates

61 with paleo-reconstructions, instrumental records, and numerical simulations. There is a 
62 lack of consensus among climate models as to how ENSO characteristics, such as

63 amplitude and flavour, will respond to future warming ${ }^{3-7}$. Nonetheless, recent studies show

64 that models that are better at capturing ENSO nonlinearity tend to simulate enhanced sea

65 surface temperature (SST) variability in the eastern equatorial Pacific ${ }^{8}$ and increased

66 frequency of events that exhibit intensified ENSO characteristics ${ }^{9,10}$. The increased

67 frequency is attributed to changes in the Pacific mean state which is marked by a weakened

68 Walker Circulation, increased upper-ocean stratification, and equatorially enhanced

69 warming that causes the Intertropical Convergence Zone (ITCZ) to be displaced

70 equatorward ${ }^{10-12}$.

71 Studies based on paleo-reconstructions have also indicated that ENSO activity is

72 sensitive to the mean climate. A synthesis of mid-Holocene ( $\sim 6 \mathrm{ka}$ [thousand years] BP)

73 records indicates a 33\% reduction in ENSO amplitude in the eastern Pacific during this

74 period $^{13}$. ENSO activity over the last millennium was shown to be weaker when compared

75 to the last half-century ${ }^{14}$, potentially suggesting global warming induced changes.

76 Furthermore, there is evidence of significantly reduced ENSO variability during the last

77 interglacial period ${ }^{15}(\sim 127 \mathrm{ka} \mathrm{BP})$. However, proxy data for the Pliocene $(\sim 5$ to $\sim 3 \mathrm{Ma}$

78 [million years] BP) are controversial on tropical Pacific changes ${ }^{16-18}$. A Pliocene El-Niño

79 like mean state has been hypothesized to reduce ENSO variability ${ }^{18}$, although there is

80 evidence of significant interannual variability during this period ${ }^{19}$. As such, tropical Pacific

81 mean state changes during the mid-Pliocene and how it has impacted ENSO activity are

82 still uncertain.

83 If there was a time in the distant past that provides an analogue to a warmer end84 of-century climate, it would be the mid-Pliocene Warm period (mPWP; 3.3Ma BP) ${ }^{20}$. 
85 The mPWP was marked by warmer SSTs of up to $9 \mathrm{~K}$ and $4 \mathrm{~K}$ in the Northern and Southern

86 Hemisphere, respectively ${ }^{21}$, compared to pre-industrial times ( 1850 Common Era), with

87 orbital forcing ${ }^{22}$ and elevated atmospheric $\mathrm{CO}_{2}$ concentrations similar to present day ${ }^{23}$

88 ( $400 \mathrm{ppm})$ while polar ice was reduced ${ }^{24}$. Partly motivated by the similarities between the

89 mPWP and scenarios of future projected warming, the Pliocene Model Intercomparison

90 Project (PlioMIP) $)^{25,26}$ initiative was developed. Here we examine the broad PlioMIP

91 ensemble, including phases 1 and 2, to better understand how ENSO activity might change

92 under warmer climates.

93

94 Reduced ENSO amplitude

95 The PlioMIP ensemble simulate a significant reduction in the amplitude of SST

96 variability across most of the global tropics (Figure 1a; see Supplementary Figure S1 for

97 PlioMIP1). In the Indian Ocean, there is a robust weakening in the western sector while no

98 significant changes in the eastern sector (Figure 1a). The tropical Atlantic shows reduced

99 SST variability in both sides of the equator likely indicating reduced variability of the

100 Atlantic Meridional Mode ${ }^{27}$ (Figure 1a). The most pronounced weakening of tropical

101 variability occurs in the equatorial Pacific (Figure 1a). The reduced amplitude in SST

102 variability in the eastern equatorial Pacific (Niño 3 region; $5^{\circ} \mathrm{N}-5^{\circ} \mathrm{S} ; 150^{\circ}-90^{\circ} \mathrm{W}$ ) is

103 simulated by 21 out of 23 PlioMIP models (including phases 1 and 2 of PlioMIP).

104 Considering PlioMIP2 models only, there is a multi-model mean amplitude reduction of

$10525 \%( \pm 16 \%$ standard deviation; Figure $1 b)$.

106 Separating the Niño3 variability change into interannual and longer timescales (>10

107 yrs) components shows that all but one model simulate reduced amplitude in the 
108 interannual band (Supplementary Figure S2), a timescale that is dominated by ENSO.

109 Additionally, 75\% (17 out of 23) of the models indicate a tendency for a shift towards

110 lower frequencies as indicated by either an increased amplitude at low-frequency $(>10 \mathrm{yr})$

111 or a more pronounced weakening at interannual than on longer time scales (Supplementary

112 Figure S2). However, changes in decadal or longer periods must be further evaluated using

113 longer timeseries data. Here due to data availability, we only use the last 100 years of each

114 model's simulation.

115

116 Role of Equatorial Pacific Ocean changes

117 ENSO dynamics is mostly dominated by equatorial processes, which are influenced by the

118 background state ${ }^{28}$. The PlioMIP models simulate a basin-wide surface warming of the

119 Equatorial Pacific (Figure 2a). The multi-model mean indicates higher levels of warming

120 in the eastern Pacific, although there are large inter-model differences in this pattern ${ }^{29}$

121 (Supplementary Figures S3 and S4). These are likely associated with differences in wind

122 changes, suggestive of wind-evaporation-SST feedback, especially in the eastern Pacific ${ }^{30}$

123 (Figure 2a, see Supplementary Figure S5 for PlioMIP1). Of particular importance for

124 ENSO dynamics are changes in equatorial thermal gradients. Recent studies have shown

125 the importance of changes in the oceanic zonal equatorial dynamics ${ }^{9,31}$ and vertical 126 equatorial gradients ${ }^{8}$ to our understand on how ENSO might change in the future.

127 Firstly, we evaluate changes in the thermocline slope as a proxy for changes in 128 equatorial ocean dynamics. Strong (weak) westward equatorial currents drive increased

129 (decreased) east-west thermocline slope, as it shoals (deepens) the eastern thermocline 130 while deepening (shoaling) its western sector ${ }^{9}$. We find that models with a steeper mean 
131 thermocline in the mPWP (i.e. a La Niña-like mean state) are typically associated with

132 larger ENSO amplitude reductions, while a flatter mean thermocline (i.e. an El Niño-like

133 state) is associated with either an slight increase or a weak decrease in ENSO variability

$134(\mathrm{r}=-0.52$; Figure $2 \mathrm{~b})$. This indicates that equatorial Pacific mean state with a steeper

135 thermocline, which corresponds to intensified ocean-atmosphere circulations, is less

136 favourable to strong ENSO variability. Under such La Niña-like mean state, stronger initial

137 anomalies are required to substantially weaken the climatological states in order to provide

138 favourable conditions for strong El Niño development 9

139 We further examine possible changes in the equatorial oceanic conditions that could

140 be unfavourable to ENSO development ${ }^{18,32}$. Ocean stratification has been hypothesized to

141 influence the variability of extreme ENSO events, as an increased ocean stratification

142 would tend to increase the dynamical coupling between the ocean and the atmosphere ${ }^{8}$. As

143 such, we evaluate ocean stratification in the central-west Pacific near the warm pool edge,

144 a region of maximum wind variability and where wind anomalies trigger ocean waves and

145 initiate ENSO development. Indeed, we find that models with decreased ocean

146 stratification are associated with major ENSO reductions, and the reduction is weaker with

147 increased ocean stratification (Figure 2c). However, an increased stratification seen in nine

148 models cannot support the fact that the ENSO variability is reduced in each of seven of

149 those models. A similar inconsistency also applies for the thermocline slope change

150 (Figure 2b). Thus, while changes in the thermocline and stratification help to explain inter-

151 model differences in ENSO amplitude changes, there must be other processes that apply

152 across models, which provide an explanation for the overall weakening of ENSO

153 variability. 


\section{Off-Equatorial Pacific changes}

156 Whilst ENSO development is closely related to the zonal equatorial dynamics ${ }^{28}$,

157 ENSO events are also affected by a variety of other large-scale processes beyond the 158 equatorial Pacific ${ }^{10,33,34}$. For instance, changes to the mean meridional SST gradient or 159 processes in the extratropics can play an important role in triggering ENSO events. In 160 particular, all PlioMIP models simulate a weaker equator-to-pole temperature gradient 161 associated with polar amplified warming ${ }^{35}$.

162 To investigate processes outside the equatorial Pacific, we first evaluate the role of 163 meridional SST gradients through possible displacements of the ITCZ in the mPWP.

164 Southward (northward) ITCZ displacements, due to changes in off-equatorial SST 165 gradients, have been shown to affect ENSO activity through increased (reduced)

166 probability of occurrences of deep convection in the central-eastern Pacific ${ }^{11}$. Here we 167 show that a mean northward ITCZ shift during austral spring-summer, i.e., during 168 developing and mature ENSO phases, is significantly related to the ENSO weakening 169 across models (Figure 3a). This northward shift in the ITCZ generally acts to supress El 170 Niño development, via a reduced probability of deep convection occurrences in the eastern

171 Pacific ${ }^{11}$. To illustrate this, we evaluate models' performance in simulating the non-linear 172 relationship between ENSO SST anomalies and anomalous precipitation events in the 173 eastern Pacific (see Methods; Supplementary Figure S6). Five models correctly simulate 174 this characteristic and indicate that the further north the mean ITCZ migrates the less 175 probable are occurrences of anomalous rainfall events in the eastern Pacific associated with 
176 ENSO SST anomalies (Figure 3b-f). The ITCZ shift can fully explain ENSO weakening

177 across these 5 models ( $r=0.99$; Supplementary Figure S7).

178 We also evaluate possible changes to the processes that are known to initiate ENSO

179 events. Firstly, the reversal of the circulation of easterly trade winds in the western Pacific

180 is known to initiate ENSO development ${ }^{36}$. In the PlioMIP models, the annual mean

181 intensification of the western Pacific trade winds corresponds with weaker wind variability

182 over this region (Figure 4a). Climatologically stronger easterly trades tend to inhibit: 1) the

183 stochastic forcing of westerly wind bursts in the western Pacific ${ }^{37}$ that triggers the positive

184 thermocline feedback; 2) southward shifts of the ITCZ through positive Wind-

185 Evaporation-SST feedback which cools the equatorial Pacific Ocean, thereby increasing

186 the meridional SST gradient; and 3) eastward displacements of the Walker circulation.

187 Secondly, we evaluate the South Pacific Meridional Mode (SPMM), which induces

188 an anomalous zonal pressure dipole across the tropical South Pacific that facilitates

189 westerly wind anomalies in the equatorial region, acting as a precursor for strong El Niño

190 events $^{34}$. We find that all but two PlioMIP2 models simulate a decreased amplitude of the

191 SPMM in the mPWP (Figure 4b). Finally, extreme El Niño events have been shown to be

192 amplified by an anomalous zonal pressure dipole in the Southern Hemisphere ${ }^{33}$. In such

193 condition, an anomalous high pressure over Australia facilitates cold surges through the

194 Coral Sea, called the Southern Hemisphere Booster (SHB) ${ }^{33}$, that promote westerly wind

195 anomalies in the western Pacific conducive for El Niño development. The meridional wind

196 variability in the SHB region also decreases in 10 out of 12 PlioMIP2 models in the mPWP

197 simulations (Figure 4c). These aforementioned changes are associated with reduced 
198 probability of El-Niño initiation that would otherwise contribute to stronger ENSO

199 variability.

$201 \quad$ Large-scale forcing

202 The Pacific ITCZ-ENSO relationship demonstrated in the previous section can be

203 either a result of a large-scale global ITCZ shift modulating ENSO or a local response of

204 the Pacific ITCZ to changes in ENSO activity. The PlioMIP models indicate that the

205 northward shift of the ITCZ during the mPWP occurs in all basins, given the typical rainfall

206 fingerprint of a meridional dipole change found across the global tropics (Figure 5a; see

207 Supplementary Figure S8 for PlioMIP1). Additionally, the PlioMIP models systematically

208 simulate polar amplified warming in both hemispheres (Figure 5b), which can give rise to

209 large-scale changes in the meridional temperature gradient and affect the ITCZ position

210 through changes in atmospheric heat fluxes ${ }^{39}$.

211 To further evaluate the cause of the ITCZ shift, we performed sensitivity

212 experiments using the NCAR Community Atmospheric Model version 4 (CAM4; See

213 Methods). The atmospheric model experiments forced with PlioMIP mean SSTs allow us

214 to isolate changes in atmospheric features and circulation, due to mPWP surface warming,

215 from changes in climate variability such as ENSO. It is worth noting the mPWP

216 climatological-mean warming pattern, used to force the atmospheric model, may still

217 contain some non-linear influence of ENSO changes, but here we assume these are

218 negligible (see Methods). We also investigate the link between the global ITCZ shift to

219 possible changes in the large-scale inter-hemispheric temperature contrast through

220 energetic constraints. 
In the present climate, during austral summer, the ITCZ shifts southwards toward

222 the equator due to increased insolation in the Southern Hemisphere of which the excess

223 heat is transported to the Northern Hemisphere (implying a northward energy flux across

224 the equator), through an intensification of the Northern Hemisphere Hadley circulation ${ }^{40}$.

225 In the mid Pliocene, the CAM4 model simulates a decreased northward heat transport

226 across the equator during the austral summer (Figure 5c). Due to the mutual relationship

227 between changes in the energy flux across the equator and ITCZ position, a decreased

228 northward energy flux at the equator is accompanied by a northward ITCZ shift. This result

229 from a reorientation of the meridional circulation of the atmosphere within the tropics.

230 Higher rates of warming in the Northern Hemisphere drive an intensification and

231 northward expansion of the Southern Hemisphere Hadley cell and weaker circulation in

232 the Northern counterpart (Figure 5d; see Supplementary Figure S8 for PlioMIP1), which

233 reduces the atmospheric energy input from the Southern to the Northern Hemisphere

234 during the austral summer.

235 The CAM4 experiments suggest that the meridional displacement of the ITCZ is a

236 global feature of the PlioMIP simulations and occurs due to the mean mPWP warming.

237 One of the most robust features of the mPWP simulations is the polar amplified warming,

238 especially in the Northern Hemisphere which increases the inter-hemispheric temperature

239 gradient (Figure 5b). However, whether the mPWP ITCZ shift is a response to tropical or

240 extratropical warming is still an open question. For instance, CAM4 experiments indicate

241 an overall decrease in the northward atmospheric heat transport (AHT) in the Northern

242 Hemisphere and overall increase in the southward AHT in the Southern Hemisphere

243 (Figure 5b), which initially points to changes in pole-to-pole temperature gradient. 
244 The large-scale changes in the meridional circulation likely induce changes in 245 horizontal circulation. Meridional displacements of the ITCZ have been shown to affect 246 trade winds in the Atlantic basin ${ }^{41}$. In the Pacific Ocean, the PlioMIP models indicate that

247 a northward ITCZ shift is significantly related to intensified western Pacific trades (Figure

248 5d), which is analogous to synchronized shifts of the Walker and Hadley circulations

249 during different ENSO phases ${ }^{42}$. An analysis of the global low-level circulation indicates

250 that the anomalously stronger western trades in the mPWP are sourced at the subtropical

251 South Pacific due to an intensified circulation of the South Pacific Subtropical High system

252 (Figure 5e; see Supplementary Figure S8 for PlioMIP1). These changes are not exclusive

253 to the South Pacific but occur in all ocean basins (Figure 5e). The synchronized changes in

254 the meridional and zonal atmospheric circulation are likely a result of global changes in

255 atmospheric heat fluxes during the warmer mPWP. Thus, this illustrates a possible

256 influence of changes in global atmospheric dynamics on ENSO in a warmer climate.

258 Discussion

259 The results presented here suggest a link between reduced ENSO amplitude and the

260 northward shift of the ITCZ in the mPWP, associated with stronger climatological

261 circulation in the Southern Hemisphere (Figure 6). The northward shift of the ITCZ reduces

262 the probability of occurrence of ENSO-related rainfall events in the eastern Pacific (Figure

263 6). Enhanced mean western Pacific trade winds are associated with reduction in the

264 variability and, thus, possibly the occurrences of stochastic westerly wind anomalies

265 (Figure 6). A strengthened Southern Hemisphere Subtropical High pressure system in the

266 Pacific, and intensified Southern Hemisphere Hadley circulation are thought to be a 
267 response to enhanced Northern Hemisphere warming through changes in the inter268 hemispheric meridional heat fluxes ${ }^{43}$ via energetic constraints for the ITCZ position ${ }^{39,44}$.

269 An intensified South Pacific Subtropical High weakens and shifts the South Pacific

270 Convergence Zone polewards ${ }^{43}$, reducing its interaction with equatorial processes, and may

271 suppress zonal sea-level pressure anomalies imposed by the South Pacific Meridional

272 Mode and the Southern Hemisphere Booster, which otherwise favour ENSO development

273 (Figure 6). As such, the climatological stability imposed by intensified tropical Southern

274 Hemisphere circulation acts to increase ENSO stability, as ENSO by definition is a

275 deviation from the mean climate, and thus stronger climatological circulations can be

276 viewed as unfavourable to ENSO-induced changes ${ }^{10}$.

277 In addition to the reduced ENSO amplitude, SST variability in other tropical basins

278 is also found to decrease (Figure 1a). This may contribute to weakened ENSO variability

279 via pan-tropical interactions ${ }^{45}$ due to a delayed and weaker negative feedback ${ }^{46,47}$, although

280 reduced variability in other tropical basins itself might also be a consequence of reduced

281 ENSO variability. For instance, an anomalously warm tropical North Atlantic is known to

282 support the initiation of La Niña events ${ }^{48}$. Pontes et al. ${ }^{27}$ reported that all PlioMIP1 models

283 simulate reduced tropical North Atlantic variability associated with a warming of this basin

284 and northward Atlantic ITCZ shift. Taken together, these results suggest that a northward

285 shift of the global ITCZ can likely mute tropical Pacific and Atlantic SST variability.

286 Our results are subject to a number of uncertainties in the simulations tied to sparse

287 and limited proxy data, which are used to constrain the PlioMIP experiments, and

288 systematic climate model biases ${ }^{49}$. Changes in the inter-hemispheric SST gradient for

289 example could be affected by uncertainties in the extension of the mPWP ice sheets ${ }^{50,51}$, 
290 poor representation of certain polar feedbacks ${ }^{52}$ (i.e. interactive land-ice), climate 291 sensitivity ${ }^{53}$, and biases in tropical convection and SST of the climate models, such as 292 double-ITCZs ${ }^{54}$ and an overly strong cold tongue. Despite data uncertainties and different

293 model biases, we show that the current generation of climate models simulate a robust 294 response of ENSO to changes in the ITCZ position in a warmer past climate.

295 With respect to future warming, paleoclimate studies have been investigating 296 whether there was a past warm climate that would serve as an analogue to the current 297 warming. Our findings indicate that, although the mPWP surface warming is comparable 298 in magnitude as projected toward the end of $21^{\text {st }}$ century under a 'business as usual' 299 scenario $(\sim 3 \mathrm{~K})^{20}$, ENSO shows an opposite response to that projected ${ }^{8,11}$. It is worth noting 300 the mPWP exemplifies an equilibrium climate with similar $\mathrm{CO}_{2}$ concentration as today, 301 indicating we could end-up in a similar-to-Pliocene climate if $\mathrm{CO}_{2}$ is maintained at present

302 levels once a steady state is reached. However, the current rate of atmospheric $\mathrm{CO}_{2}$ rise is 303 unprecedented in Earth's history, which differs from how Earth has warmed in the past.

304 Thus, linking past and future warmings is not straightforward. Here the evaluation of the 305 mPWP shows that in an empirically based equilibrium warming a northward ITCZ shift 306 drives reduced ENSO activity. If this mechanism can be applied to the $21^{\text {st }}$ century 307 projections where a southward shift of the Pacific ITCZ is projected ${ }^{10}$, then an increase in 308 ENSO variability ${ }^{8}$ in the coming decades appears to be a potential outcome. Methods

311 Models and data. Models were selected according to data availability in the PlioMIP1 and 312 PlioMIP2 databases. See Supplementary Table S1 for a list of the models included in our 
313 analysis. A total of 9 PlioMIP1 and 16 PlioMIP2 models were analysed. PlioMIP1 and

314 PlioMIP2 boundary conditions are specified in Supplementary Table S2 and describes in

315 more detail in the Supplementary Text S1. The last 100 years of each model's simulation

316 is used.

317 Statistical significance of the changes. This is measured through model agreement on the

318 sign of the change. This method is based on a binomial distribution of equal probability

319 (i.e. $\mathrm{p}=\mathrm{q}=0.5$ ). Here, we consider that all models have an equal probability of simulating

320 positive and negative changes in the mPWP simulation. As such, the cumulative

321 probability distribution function of a binomial distribution of $\mathrm{N}=9$ (PlioMIP1) and $\mathrm{N}=16$

322 (PlioMIP2) models shows that the 95\% probability level is reached when there is a model

323 agreement on the sign of the change of 7 and 11 models, respectively.

324 ENSO amplitude. The standard deviation of Niño3 index is used to represent ENSO

325 amplitude. The Niño3 index is calculated from SST anomaly averaged over the eastern

326 Pacific region between $5^{\circ} \mathrm{N}-5^{\circ} \mathrm{S}$ latitude and $150^{\circ}-90^{\circ} \mathrm{W}$ longitude.

327 Frequency separation. The amplitude of decadal or higher periods is evaluated through

328 the variance of the 11-year running mean Niño3 time series in each model. The amplitude

329 of the interannual period is estimated as the variance of the residual time series, i.e. original

330 Niño3 timeseries subtracted from the Niño3 decadal timeseries.

331 Thermocline Slope. Difference between the mean eastern Pacific thermocline depth $\left(5^{\circ} \mathrm{S}-\right.$

$\left.3325^{\circ} \mathrm{N} ; 210^{\circ}-270^{\circ} \mathrm{W}\right)$ and the western Pacific thermocline depth $\left(5^{\circ} \mathrm{S}-5^{\circ} \mathrm{N} ; 160^{\circ}-210^{\circ} \mathrm{W}\right)$. The

333 thermocline depths are computed from the mean temperature profile in each of the boxes

334 indicated above. This is the weighted average depth, based on depths in which the

335 temperature gradients are greater than $50 \%$ of its maximum. 
336 Equatorial Pacific Ocean stratification. Difference between the mean temperature in the

337 top 75 meters and the temperature at $100 \mathrm{~m}$ from $150^{\circ} \mathrm{E}$ to $140^{\circ} \mathrm{W}$, as indicated in Figure 338 2a.

339 Pacific ITCZ position ${ }^{43}$. The ITCZ position is taken as the average latitudes over which 340 precipitation over the Pacific Ocean is greater than 50\% of the maximum zonally averaged 341 precipitation over $120^{\circ} \mathrm{E}-90^{\circ} \mathrm{W}$. This method may take into account double-ITCZ and 342 double-ITCZ biases if the double-ITCZ associated precipitation is greater than $50 \%$ of the 343 maximum.

344 Criteria for model selection ${ }^{11}$. Models were selected according to their ability to simulate 345 ENSO non-linear characteristics. Selected models were required to have DJF Niño3 346 precipitation greater than $5 \mathrm{~mm}$ per day and precipitation skewness greater than 1 in the 347 pre-industrial control run. Out of 14 PlioMIP2 models, five models met these criteria 348 (Supplementary Figure S6). The skewness criterion filters out models that systematically 349 simulate overly wet and dry conditions in the eastern equatorial Pacific. These biases tend 350 to reduce rainfall skewness in the models as they simulate SSTs well below or above the 351 convective threshold of $26-28^{\circ} \mathrm{C}^{55}$, affecting Niño3 precipitation variability.

352 Atmospheric Subtropical High systems. Quantifying the intensity of the subtropical

353 highs is not a simple task when dealing with different climate backgrounds $(+2-3 \mathrm{~K})$ as the

354 global pressure weakens in a warmer atmosphere. To overcome this pressure issue, we 355 compute the streamfunction at $850 \mathrm{hPa}$ to identify the position and intensity of the 356 Subtropical High systems.

357 South Pacific Meridional Mode amplitude. Computed as the amplitude (standard 358 deviation) of mean SST anomalies from $15^{\circ} \mathrm{S}$ to $25^{\circ} \mathrm{S}$ and from $250^{\circ} \mathrm{W}$ to $260^{\circ} \mathrm{W}$. 
359 Southern Hemisphere Booster amplitude. Computed as the amplitude (standard

360 deviation) of meridional wind anomalies from $10^{\circ} \mathrm{S}$ to $30^{\circ} \mathrm{S}$ and from $140^{\circ} \mathrm{W}$ to $170^{\circ} \mathrm{W}$.

361 CAM4 experiments. We undertook four experiments, with multiple ensemble members,

362 using the NCAR Community Atmospheric Model version 4 (CAM4): 1) mean mid-

363 Pliocene SST and sea-ice forcing from PlioMIP1. PlioMIP1 SST and sea-ice were time

364 and ensemble averaged to force the CAM4 model; 2) mean pre-industrial SST and sea-ice

365 as simulated by PlioMIP1 models for comparison; experiments 3 and 4 consisted in

366 repeating experiments 1 and 2 but with PlioMIP2 SST and sea-ice. For each experiment 5

367 ensemble members were integrated with slightly different initial conditions: each ensemble

368 member was initialised from a different day of the year. The $\mathrm{CO}_{2}$ forcing was kept as pre-

369 industrial at $280 \mathrm{ppm}$ and no changes over continental areas were made in all experiments.

370 Each experiment was run for 31 years. The first year of each simulation was discarded due

371 to the atmospheric spin-up. To check if non-linearities in ENSO affected the mean SST

372 change we compared the multi-model mean mPWP warming during all years and during

373 non-ENSO years only. Differences in the tropical Pacific were approximately two orders

374 of magnitude $(<0.05 \mathrm{~K})$ lower than the mean tropical Pacific warming $(\sim 2 \mathrm{~K})$.

376 Acknowledgments

377 This work was supported by the São Paulo Research Foundation (FAPESP-Brazil grant no.

378 2016/23670-0 and no. 2019/0882-1) and the Australian Research Council (ARC

379 FT160100495) including the ARC Centre of Excellence for Climate Extremes

380 (CE110001028) and the NCI National Facility, Canberra. PlioMIP2 experiments were

381 supported by FP7 Ideas Programme: European Research Council, Past Earth Network, 
382 CEMAC - University of Leeds, JSPS, Earth Simulator at JAMSTEC, Helmholtz Climate 383 Initiative REKLIM, Alfred Wegener Institute's research programme Marine, Coastal and

384 Polar Systems, Swedish Research Council, Swedish National Infrastructure for 385 Computing, Canadian Innovation Foundation, UNINETT Sigma2 - the National

386 Infrastructure for High Performance Computing and Data Storage in Norway, Très Grand

387 Centre de calcul du CEA - GENCI, National Science Foundation (NSF - USA), SURFsara

388 Dutch National Computing and Netherlands Organisation for Scientific Research, Exact

389 Sciences.

390 Author contributions

391 GMP, AST, ASG and AS designed the study. GMP, AST, ASG, AS and IW contributed

392 to the interpretation of the data and discussions. GMP conducted the analysis, prepared the

393 figures and wrote the original manuscript. ASG produced the schematic in Figure 6. GMP

394 and AST performed the CAM4 experiments. The remaining authors performed the 395 PlioMIP2 simulations and commented on the manuscript.

397 Competing Interests

398 The authors declare no competing interests.

400 Code availability

401 Computer codes are available upon request to Gabriel M. Pontes (gabrielpontes@usp.br). 402

403 Data availability

404 
PlioMIP2 data (with exception of IPSLCM6A and GISS2.1G) is available upon request to

406 Alan M. Haywood (a.m.haywood@leeds.ac.uk). PlioMIP2 data from CESM2, EC-

407 Earth3.3, NorESM1-F, IPSLCM6A and GISS2.1G can be obtained directly through the

408 Earth System Grid Federation repository (ESGF; https://esgf-node.llnl.gov/search/cmip6/).

409

410 References

411 1. McPhaden, M. J., Zebiak, S. E. \& Glantz, M. H. ENSO as an integrating concept

$412 \quad$ in earth science. Science 314, 1740-1745 (2006).

413 2. Santoso, A. et al. Dynamics and predictability of El Niño-Southern oscillation: An

414 Australian perspective on progress and challenges. Bull. Am. Meteorol. Soc. 100,

415 403-420 (2019).

416 3. van Oldenborgh, G. J., Philip, S. Y. \& Collins, M. El Niño in a changing climate: a

417 multi-model study. Ocean Sci. 1, 81-95 (2005).

418 4. Collins, M. et al. The impact of global warming on the tropical Pacific Ocean and

$419 \quad$ El Nĩo. Nat. Geosci. 3, 391-397 (2010).

420

421

422

423

424

425

426

427

428

429

430

431

432

433

434

435

436

437

438

439

440

441

442

443

5. Kim, S. T. \& Yu, J. The two types of ENSO in CMIP5 models. Geophys. Res. Lett. 39, (2012).

6. Stevenson, S. L. Significant changes to ENSO strength and impacts in the twentyfirst century: Results from CMIP5. Geophys. Res. Lett. 39, (2012).

7. Taschetto, A. S. et al. Cold Tongue and Warm Pool ENSO Events in CMIP5: Mean State and Future Projections. J. Clim. 27, 2861-2885 (2014).

8. Cai, W. et al. Increased variability of eastern Pacific El Niño under greenhouse warming. Nature 564, 201-206 (2018).

9. Santoso, A. et al. Late-twentieth-century emergence of the El Niño propagation asymmetry and future projections. Nature 504, 126-130 (2013).

10. Cai, W. et al. ENSO and greenhouse warming. Nature Climate Change 5, 849-859 (2015).

11. Cai, W. et al. Increasing frequency of extreme El Niño events due to greenhouse warming. Nat. Clim. Chang. 4, 111-116 (2014).

12. Mamalakis, A. et al. Zonally contrasting shifts of the tropical rain belt in response to climate change. Nat. Clim. Chang. 1-9 (2021). doi:10.1038/s41558-020-00963$\mathrm{x}$

13. Emile-Geay, J. et al. Links between tropical Pacific seasonal, interannual and orbital variability during the Holocene. Nature Geoscience 9, 168-173 (2016).

14. Grothe, P. R. et al. Enhanced El Niño-Southern Oscillation variability in recent decades. Geophys. Res. Lett. (2019). doi:10.1029/2019g1083906

15. Tierney, J. E. et al. Past climates inform our future. Science (80-. ). 370, (2020).

16. Rickaby, R. E. M. \& Halloran, P. Cool La Niña during the warmth of the Pliocene? Science (80-. ). 307, 1948-1952 (2005).

444 17. Wara, M. W., Ravelo, A. C. \& Delaney, M. L. Permanent El Niño-like Conditions 
during the Pliocene Warm Period. Source Sci. New Ser. 309, 758-761 (2005)

18. Brierley, C. M. et al. Greatly Expanded Tropical Warm Pool and Waekened Hadley Circulation in the Early Pliocene. Science (80-. ). 323, 1714-1718 (2009).

19. Watanabe, T. et al. Permanent El Niño during the Pliocene warm period not supported by coral evidence. Nature 471, 209-211 (2011).

20. Burke, K. D. et al. Pliocene and Eocene provide best analogs for near-future climates. Proc. Natl. Acad. Sci. U. S. A. 115, 13288-13293 (2018).

21. Yan, Q., Wang, H., Johannessen, O. M. \& Zhang, Z. Greenland ice sheet contribution to future global sea level rise based on CMIP5 models. Adv. Atmos. Sci. 31, 8-16 (2014).

22. Haywood, A. M., Dowsett, H. J. \& Dolan, A. M. Intregation geological archives and climate models for the mid-Pliocene warm period. Nat. Commun. 6, 1-14 (2016).

23. Seki, O. et al. Alkenone and boron-based Pliocene pCO2 records. Earth Planet. Sci. Lett. 292, 201-211 (2010).

24. Hill, D. J. et al. Evaluating the dominant components of warming in Pliocene climate simulations. Clim. Past 10, 79-90 (2014).

25. Haywood, A. M. et al. Pliocene Model Intercomparison Project ( PlioMIP ): experimental design and boundary conditions ( Experiment 2 ). Geosci. Model Dev. 4, 571-577 (2011).

26. Haywood, A. M. et al. The Pliocene Model Intercomparison Project ( PlioMIP ) Phase 2 : scientific objectives and experimental design. Clim. Past 12, 663-675 (2016).

27. Pontes, G. M., Wainer, I., Prado, L. \& Brierley, C. Reduced Atlantic variability in the mid-Pliocene. Clim. Change 160, 445-461 (2020).

28. Jin, F. F., Kim, S. T. \& Bejarano, L. A coupled-stability index for ENSO. Geophys. Res. Lett. 33, L23708 (2006).

29. Oldeman, A. M. et al. Reduced El-Niño variability in the mid-Pliocene according to the PlioMIP2 ensemble. in prep. (2021).

30. Xie, S.-P. et al. Global Warming Pattern Formation: Sea Surface Temperature and Rainfall. J. Clim. 23, 966-986 (2010).

31. Wang, B. et al. Historical change of El Niño properties sheds light on future changes of extreme El Niño. Proc. Natl. Acad. Sci. U. S. A. 116, 22512-22517 (2019).

32. Manucharyan, G. E. \& Fedorov, A. V. Robust ENSO across a wide range of climates. J. Clim. 27, 5836-5850 (2014).

33. Hong, L.-C., LinHo \& Jin, F.-F. A Southern Hemisphere booster of super El Niño. Geophys. Res. Lett. 41, 2142-2149 (2014).

34. Larson, S. \& Kirtman, B. The Pacific Meridional Mode as a trigger for ENSO in a high-resolution coupled model. Geophys. Res. Lett. 40, 3189-3194 (2013).

35. Haywood, A. M. et al. The Pliocene Model Intercomparison Project Phase 2: large-scale climate features and climate sensitivity. Clim. Past 16, 2095-2123 (2020).

36. Timmermann, A. et al. El Niño-Southern Oscillation complexity. Nature 559, 535-545 (2018).

37. Chen, D. et al. Strong influence of westerly wind bursts on El Niño diversity. 
Nature Geoscience 8, 339-345 (2015).

38. Haywood, A. M. et al. Large-scale features of Pliocene climate: Results from the Pliocene Model Intercomparison Project. Clim. Past 9, 191-209 (2013).

39. Schneider, T., Bischoff, T. \& Haug, G. H. Migrations and dynamics of the intertropical convergence zone. Nature 513, 45-53 (2014).

40. Donohoe, A., Marshall, J., Ferreira, D. \& Mcgee, D. The Relationship between ITCZ Location and Cross-Equatorial Atmospheric Heat Transport: From the Seasonal Cycle to the Last Glacial Maximum. J. Clim. June, 3597-3618 (2013).

41. Mcgee, D. et al. Hemispherically asymmetric trade wind changes as signatures of past ITCZ shifts. Quat. Sci. Rev. 180, 214-228 (2018).

42. Yun, K. S., Timmermann, A. \& Stuecker, M. Synchronized spatial shifts of Hadley and Walker circulations. Earth Syst. Dyn. 12, 121-132 (2021).

43. Pontes, G. M. et al. Drier tropical and subtropical Southern Hemisphere in the mid-Pliocene Warm Period. Sci. Rep. 10, 13458 (2020).

44. Chiang, J. C. H. \& Friedman, A. R. Extratropical Cooling, Interhemispheric Thermal Gradients, and Tropical Climate Change. Annu. Rev. Earth Planet. Sci. 40, 383-412 (2012).

45. Cai, W. et al. Pantropical climate interactions. Science 363, eaav4236 (2019).

46. Dommenget, D. \& Yu, Y. The effects of remote SST forcings on ENSO dynamics, variability and diversity. Clim. Dyn. 49, 2605-2624 (2017).

47. Dommenget, D., Semenov, V. \& Latif, M. Impacts of the tropical Indian and Atlantic Oceans on ENSO. Geophys. Res. Lett. 33, 2006GL025871 (2006).

48. Ham, Y. G., Kug, J. S., Park, J. Y. \& Jin, F. F. Sea surface temperature in the north tropical Atlantic as a trigger for El Niño/Southern Oscillation events. Nat. Geosci. 6, 112-116 (2013).

49. Fedorov, A. V. et al. Patterns and mechanisms of early Pliocene warmth. Nature 496, 43-49 (2013).

50. Koenig, S. J. et al. Ice sheet model dependency of the simulated Greenland Ice Sheet in the mid-Pliocene. Clim. Past 11, 369-381 (2015).

51. Et al., T. N. Obliquity-paced Pliocene West Antarctic ice sheet oscillations. Nature 458, 322-329 (2009).

52. Fischer, H. et al. Palaeoclimate constraints on the impact of $2{ }^{\circ} \mathrm{c}$ anthropogenic warming and beyond. Nature Geoscience 11, 474-485 (2018).

53. Zhu, J., Poulsen, C. J. \& Otto-Bliesner, B. L. High climate sensitivity in CMIP6 model not supported by paleoclimate. Nature Climate Change 10, 378-379 (2020).

54. Tian, B. \& Dong, X. The Double-ITCZ Bias in CMIP3, CMIP5 and CMIP6 Models Based on Annual Mean Precipitation. Geophys. Res. Lett. e2020GL087232 (2020). doi:10.1029/2020GL087232

55. Johnson, N. C. \& Xie, S. P. Changes in the sea surface temperature threshold for tropical convection. Nat. Geosci. 3, 842-845 (2010). 


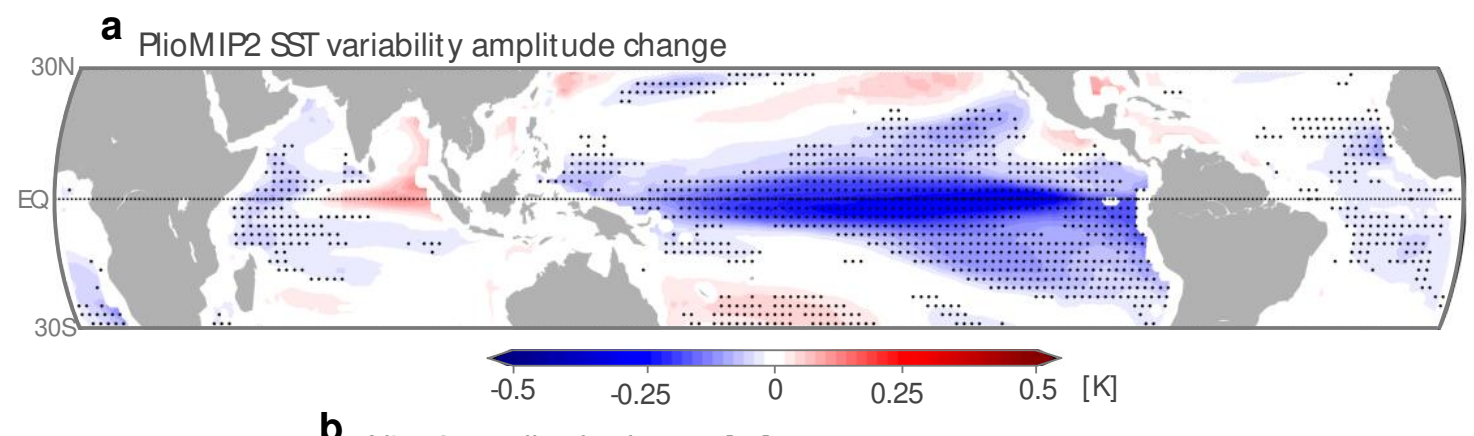

b Niño3 amplitude change [\%]

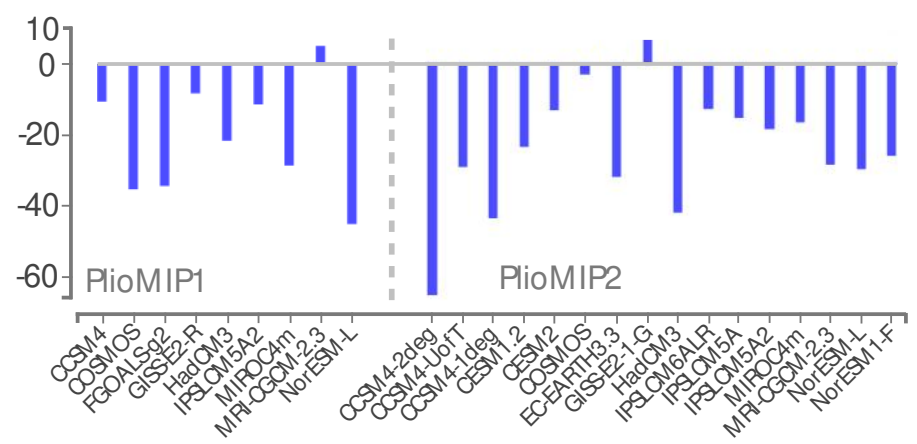

540 Figure 1 - Simulated Mid-Pliocene tropical variability changes. a) multi-model mean 541 change in the amplitude (variance) of SST variability in the PlioMIP2 models (see 542 Supplementary Figure S1 for PlioMIP1 models). Stippling indicates locations where there 543 is a significant model agreement (at least 70\%) in the sign of the change. b) change in the 544 amplitude (standard deviation) of the Niño3 $\left(5^{\circ} \mathrm{S}-5^{\circ} \mathrm{N} ; 210^{\circ}-270^{\circ} \mathrm{E}\right)$ time series in each 545 PlioMIP model. 


\section{a}

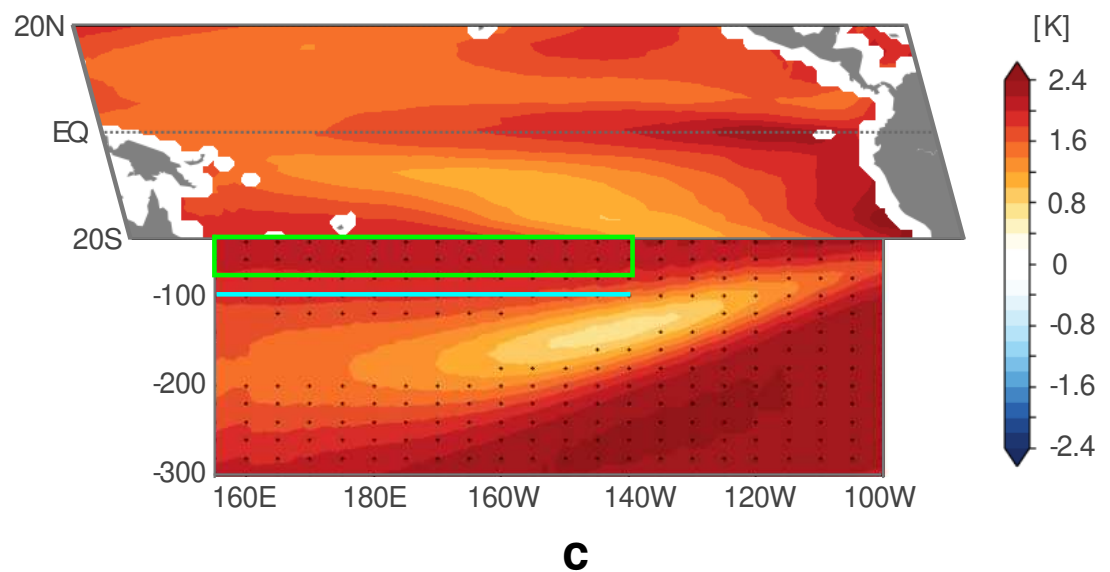

b

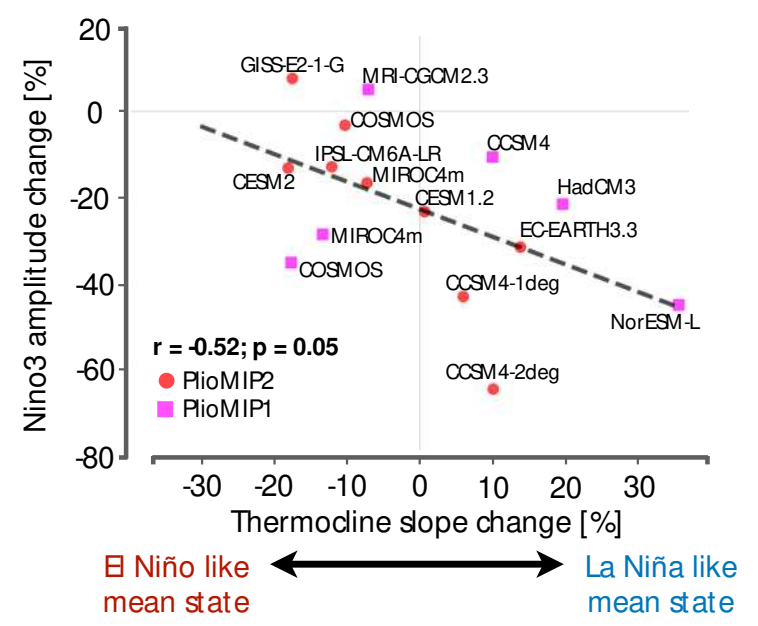

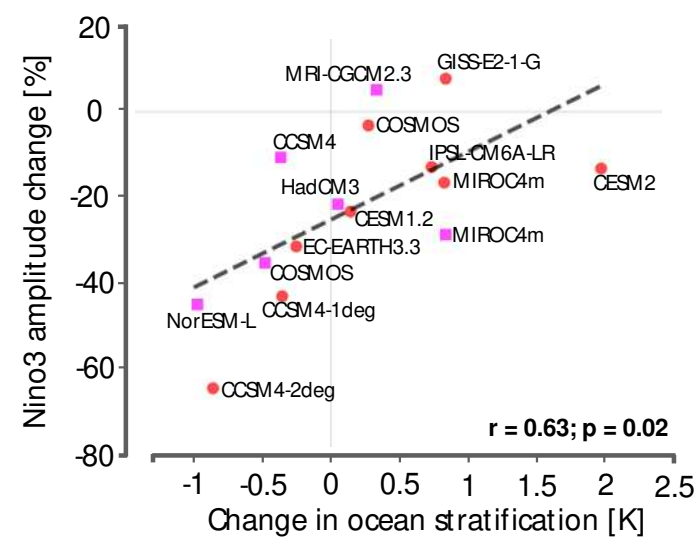

546

547

548

549

550

551

552

553

554

555

556

557

558
Figure 2 - Equatorial Pacific Ocean changes. a) PlioMIP2 multi-model mean change in surface tropical and sub-surface equatorial Pacific temperatures. The vertical profile is averaged between $5^{\circ} \mathrm{S}$ and $5^{\circ} \mathrm{N}$. Stippling indicates significant change at the $95 \%$ level (in the SST panel the entire basin-wide warming is significant at the $95 \%$ level). See Supplementary Figures S3 and S4 for individual PlioMIP2 models and Supplementary Figures S5 and S6 for PlioMIP1 models. b) inter-model relationship between the change in the thermocline slope between the eastern and western Pacific (see Methods) and the change in the Niño3 amplitude. c) inter-model relationship between the change in ocean stratification and in the Niño3 amplitude. Ocean stratification was measured as the difference between the average temperature in the top $75 \mathrm{~m}$ (green box, panel a) and at $100 \mathrm{~m}$ (blue line), from $150^{\circ} \mathrm{E}$ to $140^{\circ} \mathrm{W}$. 

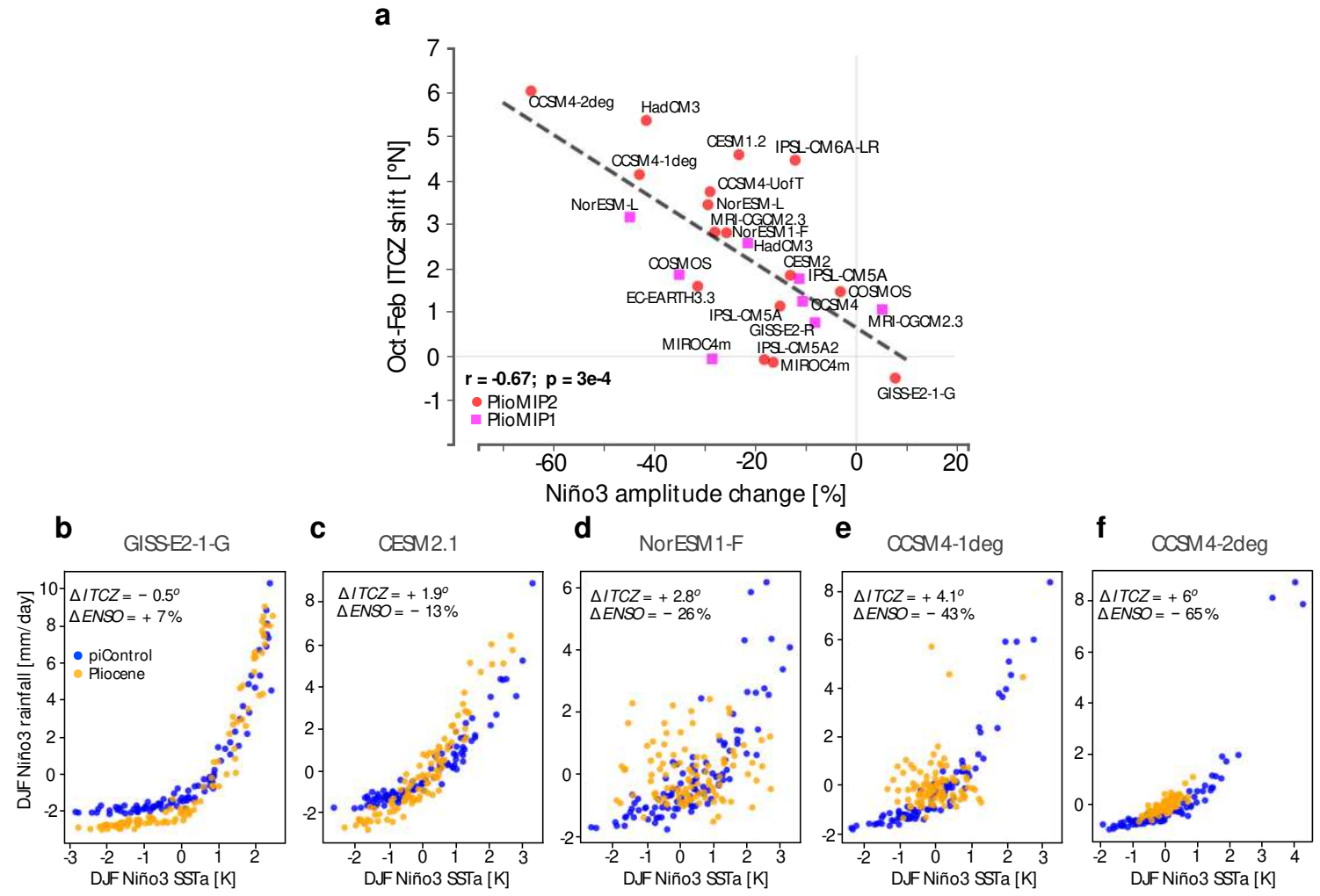

560 Figure 3 - ENSO-ITCZ inter-model relationship. a) PlioMIP2 inter-model relationship 561 between the change in the Niño3 amplitude and mean ITCZ shift from October to February. 562 b) to f) model relationship between DJF Niño3 SST anomalies and DJF Niño3 rainfall 563 anomalies for pre-industrial (blue) and mid-Pliocene simulations (yellow). Models were 564 selected according to their ability to simulate non-linear ENSO characteristics (See 565 Methods). PlioMIP1 precipitation data for the last 100 years was not available so these 566 models could not be included in this analysis (see Methods). 
b

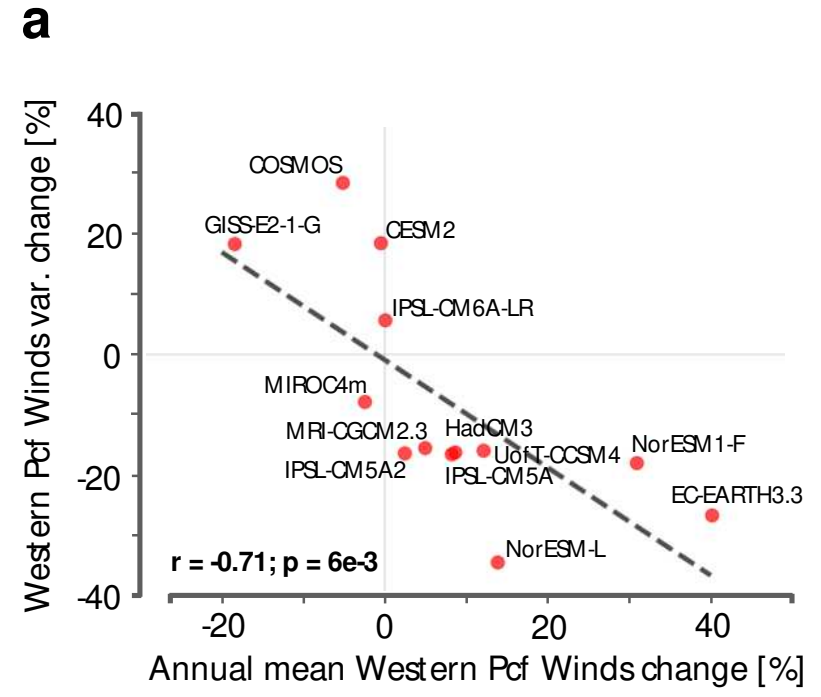

570

571 Figure 4 - Changes to potential ENSO triggers. a) inter-model relationship between the 572 change in the intensity of the western Pacific trade winds (from $160^{\circ} \mathrm{E}$ to $150^{\circ} \mathrm{W}$ and from $57310^{\circ} \mathrm{S}$ to $10^{\circ} \mathrm{N}$ ) and the amplitude (standard deviation) of its monthly variability. To ideally 574 examine changes in the western wind bursts we would daily output, however high 575 frequency output was not available for the PlioMIP models. b) Change in the amplitude 576 (standard deviation) of the South Pacific Meridional mode time series, defined as the mean 577 SST anomaly between $15^{\circ} \mathrm{S}-25^{\circ} \mathrm{S}$ and $250^{\circ} \mathrm{W}-260^{\circ} \mathrm{W}$. c) Change in the amplitude (standard 578 deviation) of the meridional wind variability over the Southern Hemisphere Booster region 579 (from $10^{\circ} \mathrm{S}$ to $30^{\circ} \mathrm{S}$ and from $140^{\circ} \mathrm{W}$ to $170^{\circ} \mathrm{W}$ ). PlioMIP2 models in panels 'b' and 'c': a 580 - CCSM4-UofT; b - CCSM4-2deg; c - CESM2; d - COSMOS; e - EC-EARTH3.3; f 581 GISS-E2-1-G; g - HadCM3; h - IPSL-CM6A-LR; i - IPSL-CM5A; j - IPSL-CM5A2; $\mathrm{k}$ 582 - MIROC4m; 1 - MRI-CGCM2.3; m - NorESM-L; $\mathrm{n}$ - NorESM1-F. 

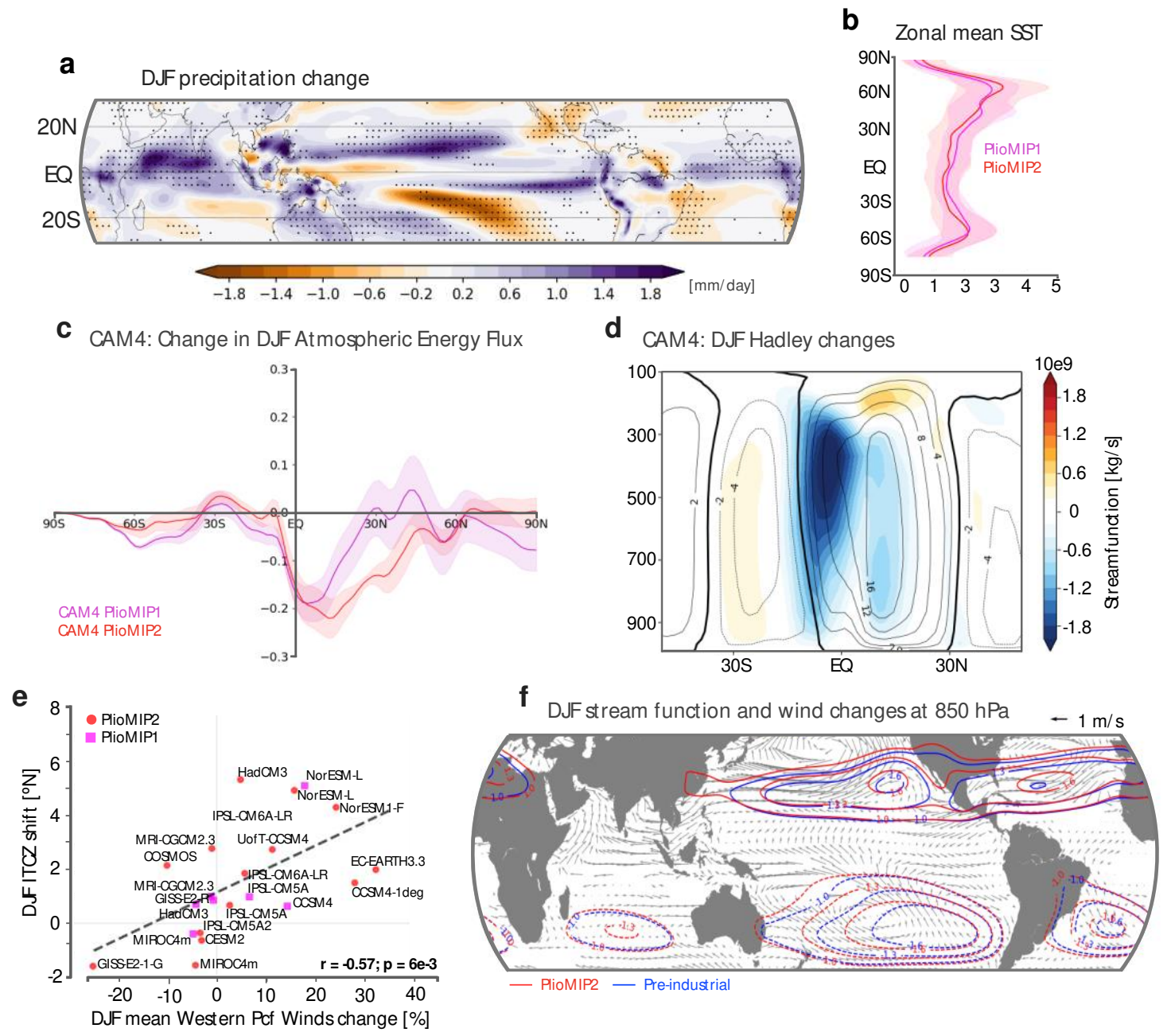

Figure 5 - Energetics constraints for the ITCZ position. a) DJF precipitation change in the PlioMIP2 models (mPWP minus pre-industrial). Stippling indicates where the change is significant at the $95 \%$ level. b) multi-model mean change zonally averaged SST for the 588 PlioMIP1 (magenta) and PLioMIP2 (red). Banding indicates standard deviation range. c) 589 Changes in DJF atmospheric energy flux, computed as the residual between the total topof-the-atmosphere and surface energy fluxes, in the CAM4 experiments forced with PlioMIP1 and 2 climatological SST and sea-ice (see Methods). Banding indicates standard deviation range of a 5 -member ensemble. d) Changes in the meridional streamfunction in the CAM4 experiment forced with PlioMIP2 SST and sea-ice (see Methods). y-axis: Pressure [mb]. Contours indicate pre-industrial streamfunction (zero contour in bold). Colours indicate change (mPWP minus pre-industrial) e) Inter-model relationship between changes in the intensity of the zonal western Pacific trades and ITCZ shift during austral summer. $\mathrm{f})$ Changes in global low-level $(850 \mathrm{hPa})$ winds and stream function in the 600 PlioMIP2 models. Wind changes are only plotted where there is a significant change at the $95 \%$ level. 


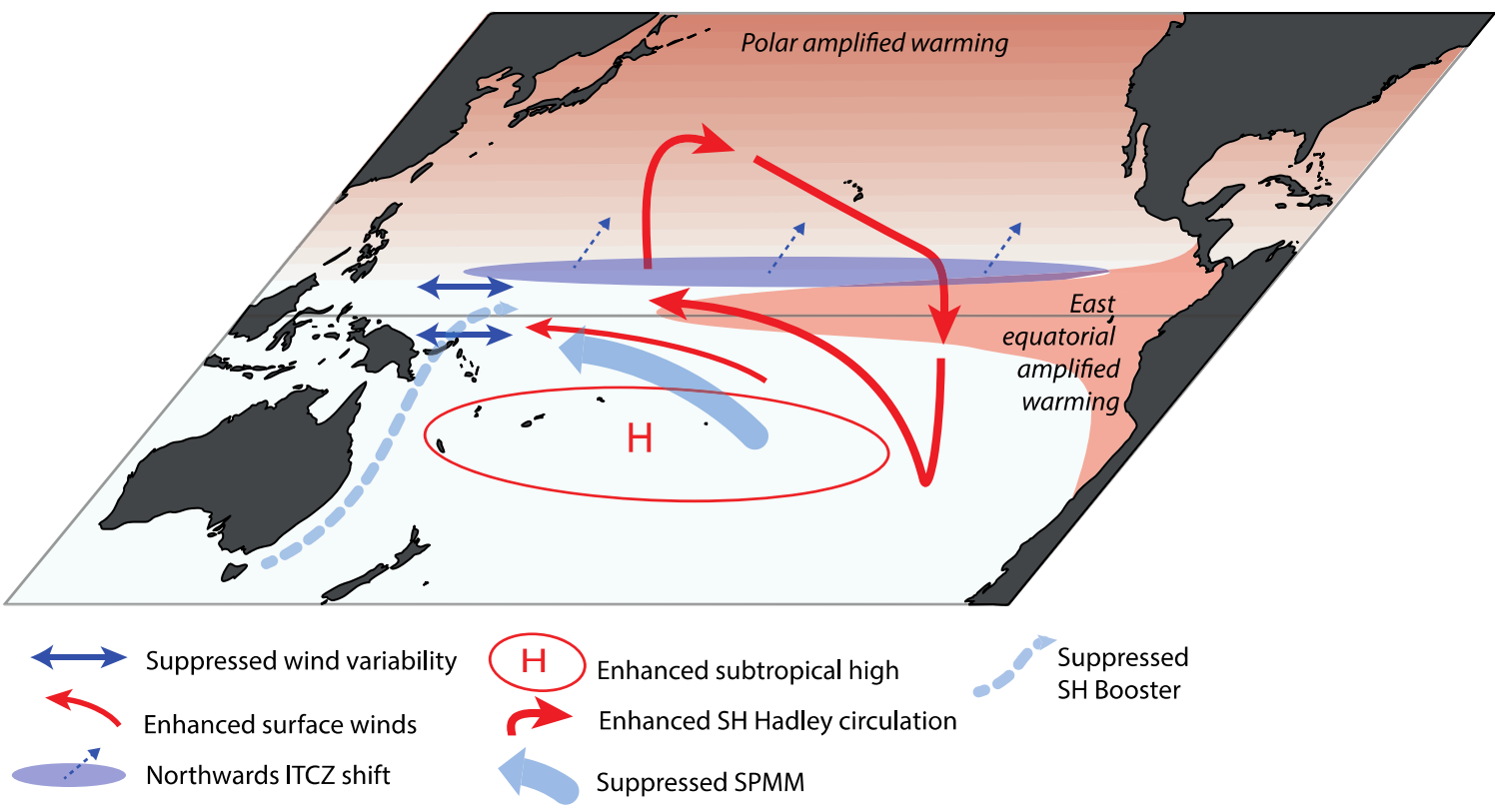

604 Figure 6 - Schematic of the drivers of suppressed ENSO activity in the mPWP. A 605 northward ITCZ shift reduces the probability of occurrence of deep convection in the 606 central-eastern Pacific. Energetic constrains for the ITCZ position indicates that higher 607 rates of warming in Northern Hemisphere drive a northward ITCZ shift and intensified 608 enhanced Southern Hemisphere Hadley circulation. These changes are also associated with 609 enhanced subtropical high and intensified western Pacific trades. Enhanced trade winds 610 suppress wind variability in the western Pacific, which are important for El Niño initiation. 611 An intensified subtropical high is thought to impede zonal pressure anomalies across the 612 tropical South Pacific and, thus, suppress the activity of the South Pacific Meridional Mode 613 (SPMM) and Southern Hemisphere Booster that are important for the development of 614 strong El Niño events. 


\section{Figures}
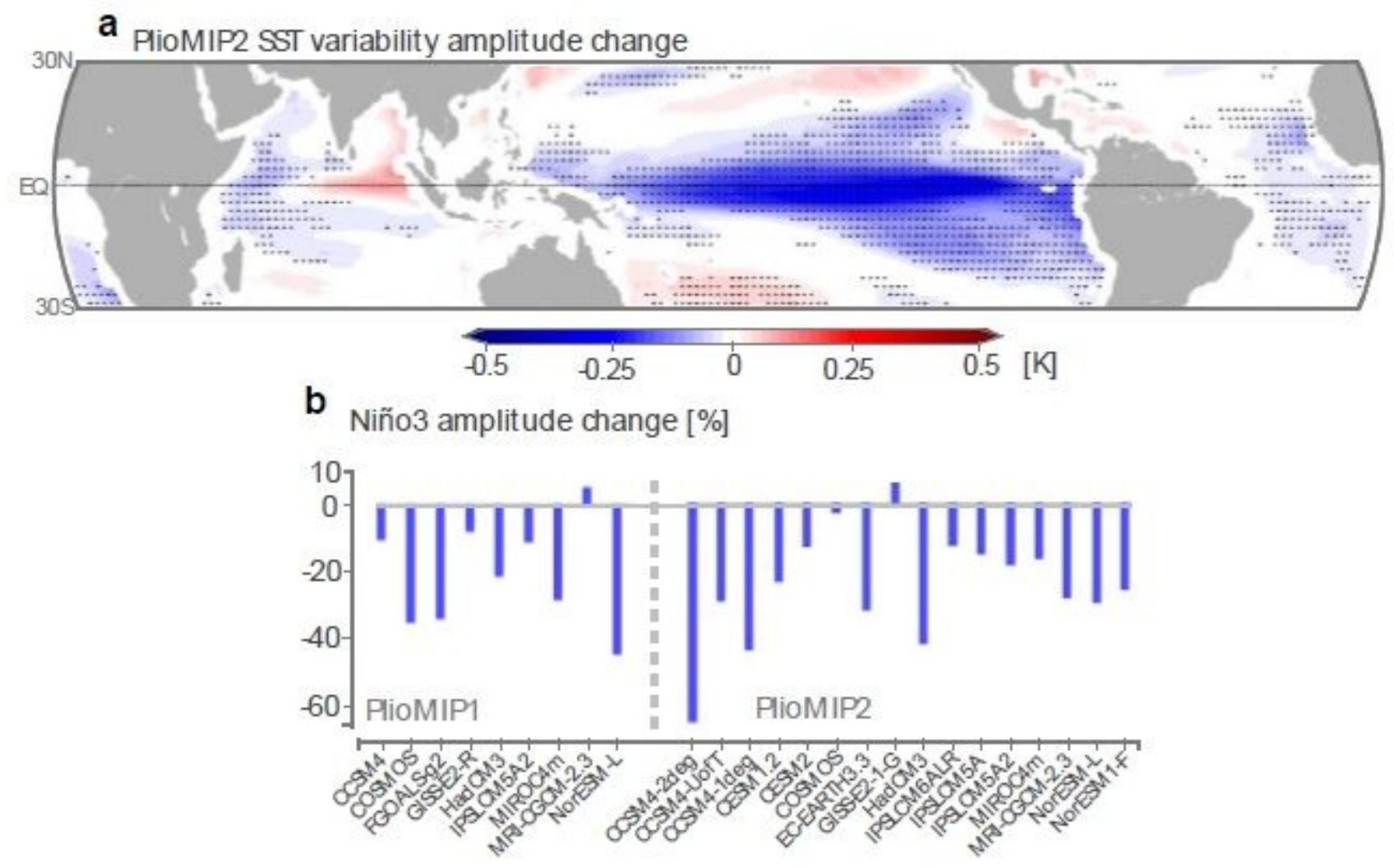

\section{Figure 1}

Simulated Mid-Pliocene tropical variability changes. a) multi-model mean change in the amplitude (variance) of SST variability in the PlioMIP2 models (see Supplementary Figure S1 for PlioMIP1 models). Stippling indicates locations where there is a significant model agreement (at least 70\%) in the sign of the change. b) change in the amplitude (standard deviation) of the Niño3 $\left(5^{\circ} \mathrm{S}-5^{\circ} \mathrm{N} ; 210^{\circ}-270^{\circ} \mathrm{E}\right)$ time series in each PlioMIP model. Note: The designations employed and the presentation of the material on this map do not imply the expression of any opinion whatsoever on the part of Research Square concerning the legal status of any country, territory, city or area or of its authorities, or concerning the delimitation of its frontiers or boundaries. This map has been provided by the authors. 


\section{a}

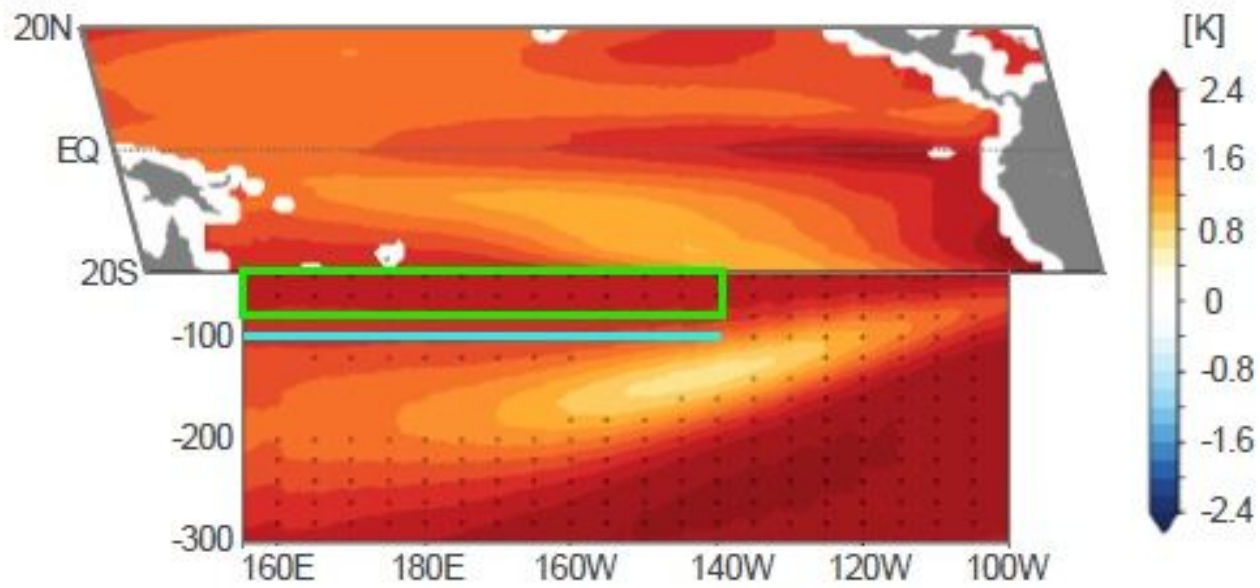

b

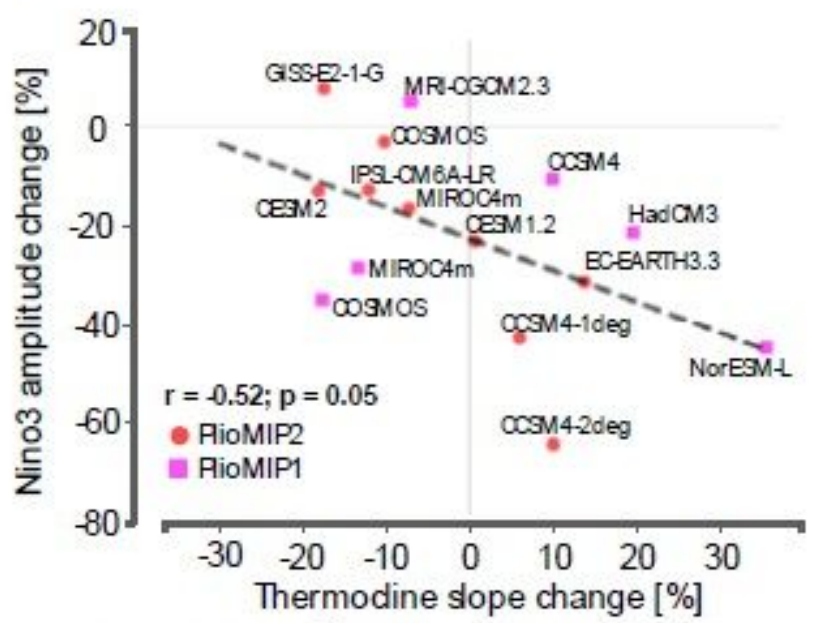

日 Niño like mean state
C

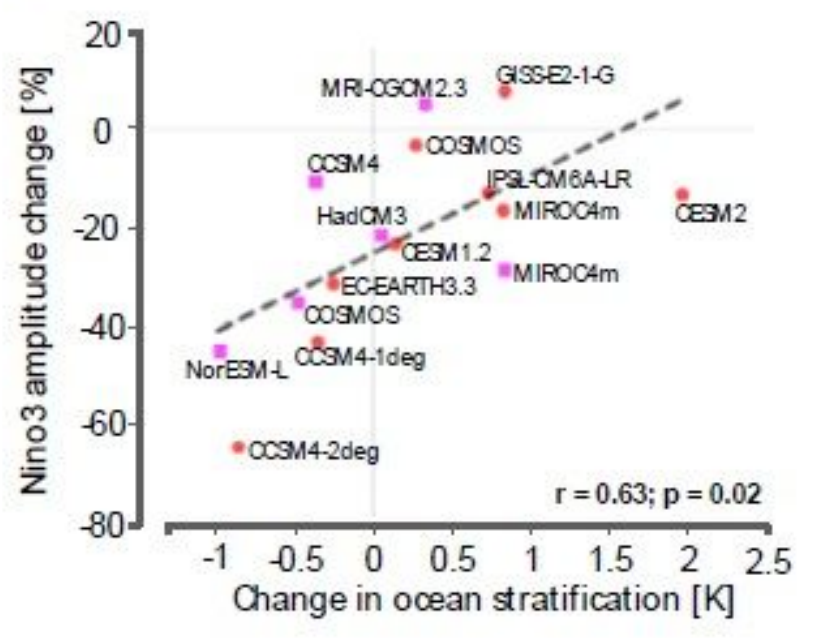

\section{Figure 2}

Equatorial Pacific Ocean changes. a) PlioMIP2 multi-model mean change in surface tropical and subsurface equatorial Pacific temperatures. The vertical profile is averaged between $5^{\circ} \mathrm{S}$ and $5^{\circ} \mathrm{N}$. Stippling indicates significant change at the $95 \%$ level (in the SST panel the entire basin-wide warming is significant at the $95 \%$ level). See Supplementary Figures S3 and S4 for individual PlioMIP2 models and Supplementary Figures S5 and S6 for PlioMIP1 models. b) inter-model relationship between the change in the thermocline slope between the eastern and western Pacific (see Methods) and the change in the Niño3 amplitude. c) inter-model relationship between the change in ocean stratification and in the Niño3 amplitude. Ocean stratification was measured as the difference between the average temperature in the top $75 \mathrm{~m}$ (green box, panel a) and at $100 \mathrm{~m}$ (blue line), from $150^{\circ} \mathrm{E}$ to $140^{\circ} \mathrm{W}$. 

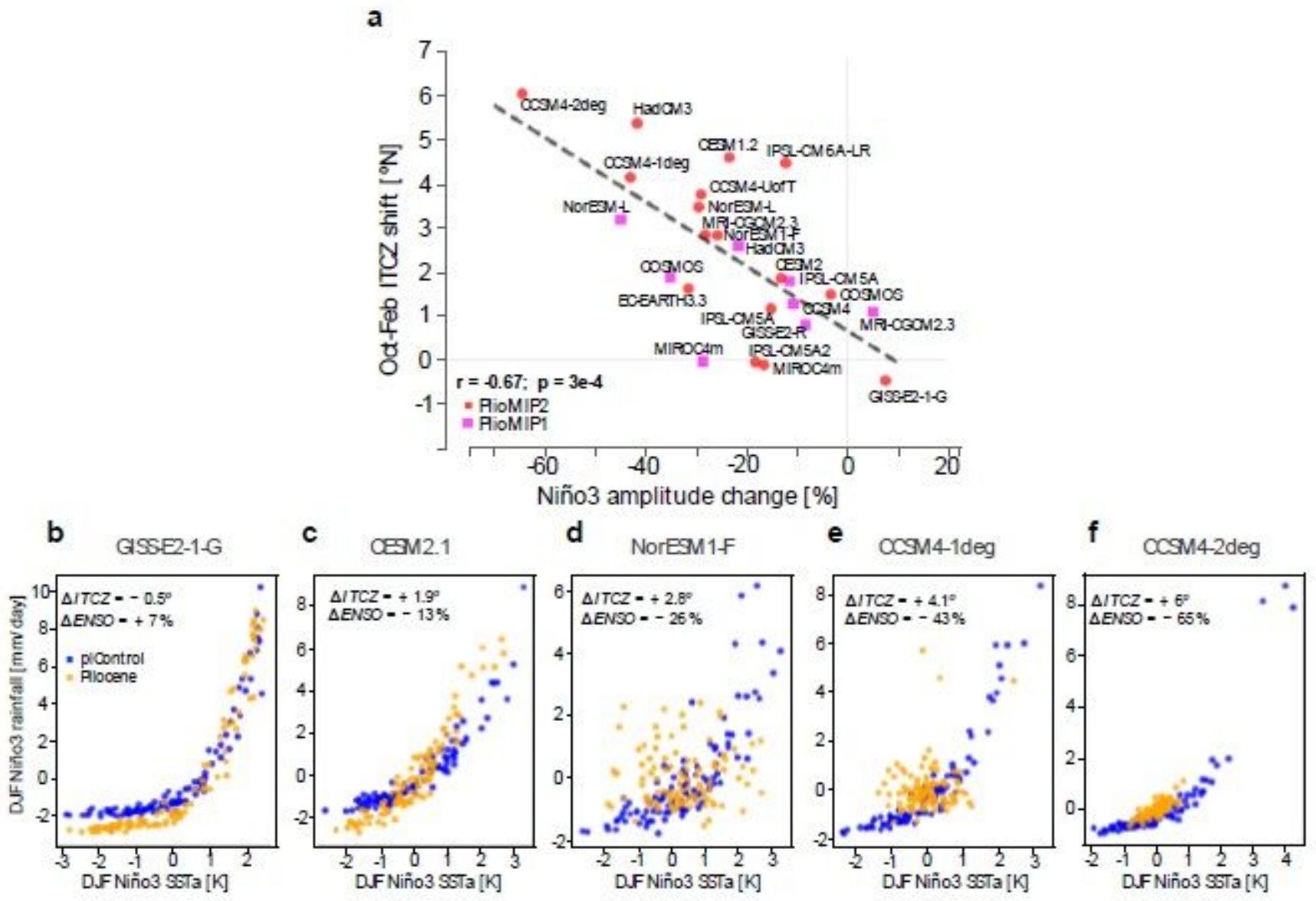

\section{Figure 3}

ENSO-ITCZ inter-model relationship. a) PlioMIP2 inter-model relationship between the change in the Niño3 amplitude and mean ITCZ shift from October to February. b) to f) model relationship between DJF Niño3 SST anomalies and DJF Niño3 rainfall anomalies for pre-industrial (blue) and mid-Pliocene simulations (yellow). Models were selected according to their ability to simulate non-linear ENSO characteristics (See Methods). PlioMIP1 precipitation data for the last 100 years was not available so these models could not be included in this analysis (see Methods). 


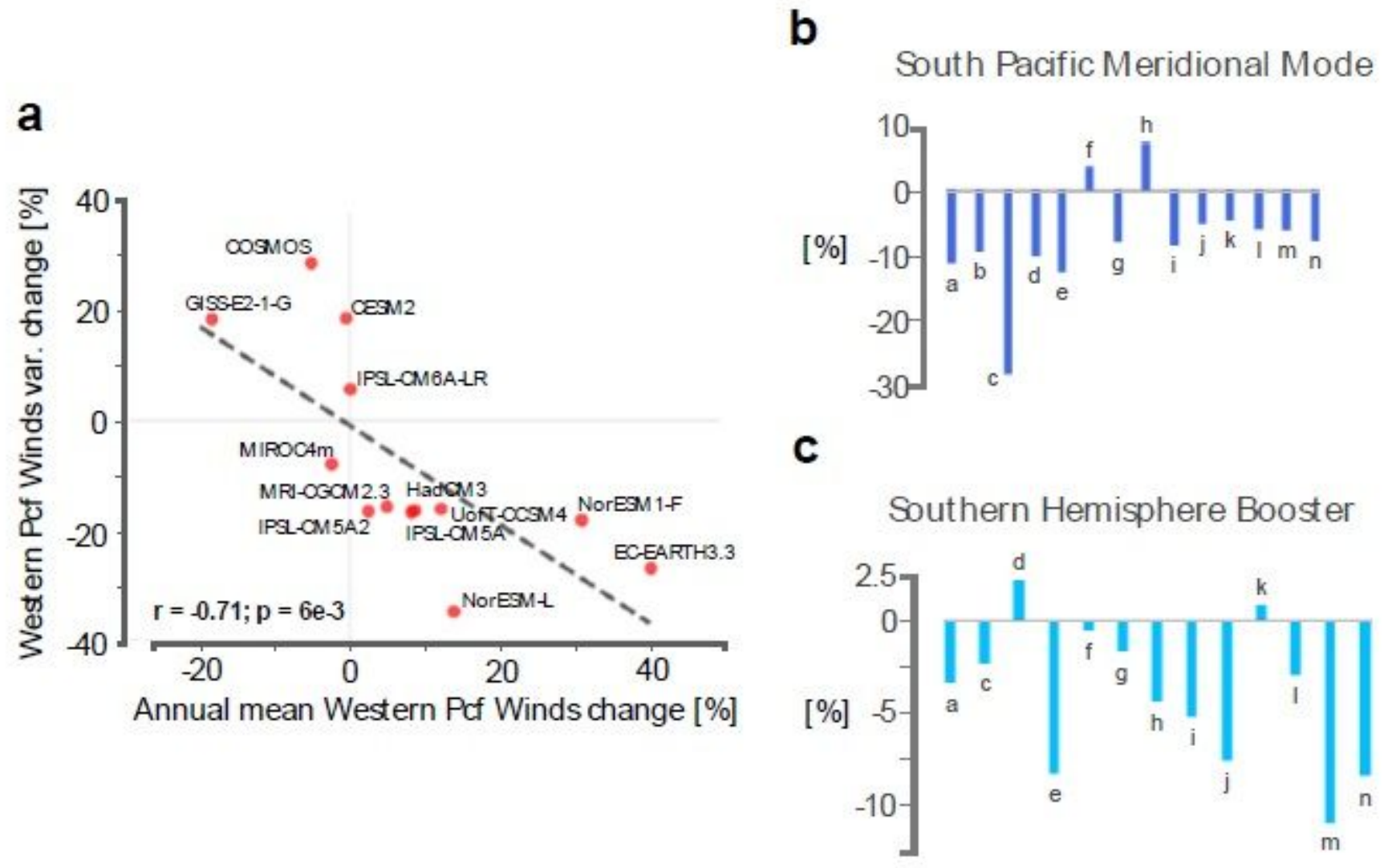

Figure 4

Changes to potential ENSO triggers. a) inter-model relationship between the change in the intensity of the western Pacific trade winds (from $160^{\circ} \mathrm{E}$ to $150^{\circ} \mathrm{W}$ and from $10^{\circ} \mathrm{S}$ to $10^{\circ} \mathrm{N}$ ) and the amplitude (standard deviation) of its monthly variability. To ideally examine changes in the western wind bursts we would daily output, however high frequency output was not available for the PlioMIP models. b) Change in the amplitude (standard deviation) of the South Pacific Meridional mode time series, defined as the mean SST anomaly between $15^{\circ} \mathrm{S}-25^{\circ} \mathrm{S}$ and $250^{\circ} \mathrm{W}-260^{\circ} \mathrm{W}$. c) Change in the amplitude (standard deviation) of the meridional wind variability over the Southern Hemisphere Booster region (from $10^{\circ} \mathrm{S}$ to $30^{\circ} \mathrm{S}$ and from $140^{\circ} \mathrm{W}$ to $170^{\circ} \mathrm{W}$ ). PlioMIP2 models in panels ' $b$ ' and ' $c$ ': $a$ - CCSM4-UofT; $b$ - CCSM4-2deg; c - CESM2; d - COSMOS; e - EC-EARTH3.3; f - GISS-E2-1-G; g - HadCM3; h - IPSL-CM6A-LR; i - IPSL-CM5A; j IPSL-CM5A2; k - MIROC4m; I - MRI-CGCM2.3; m - NorESM-L; n - NorESM1-F. 
a D.Fprecipitation change
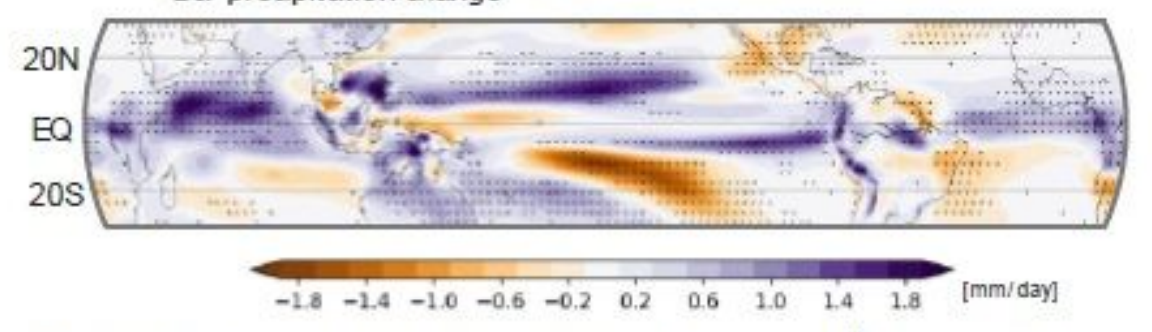

C CAM4: Change in D.FAtmospheric Energy Hux

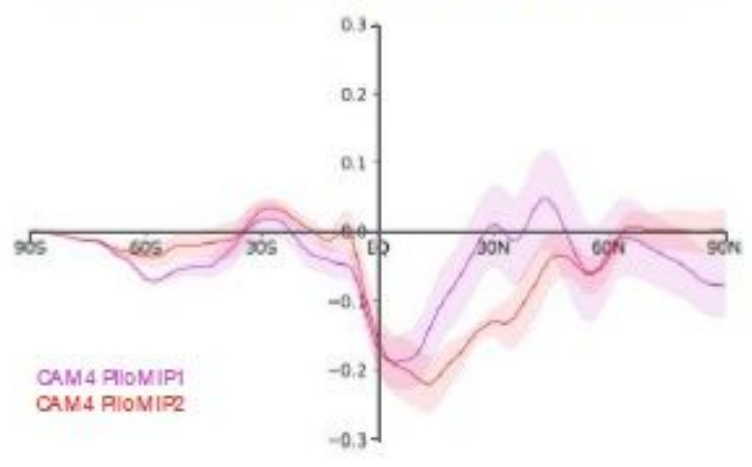

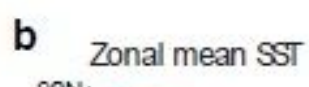

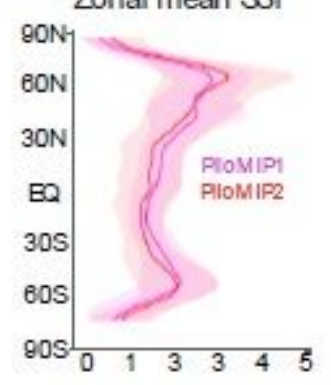

d CAM4: DF Hadley changes

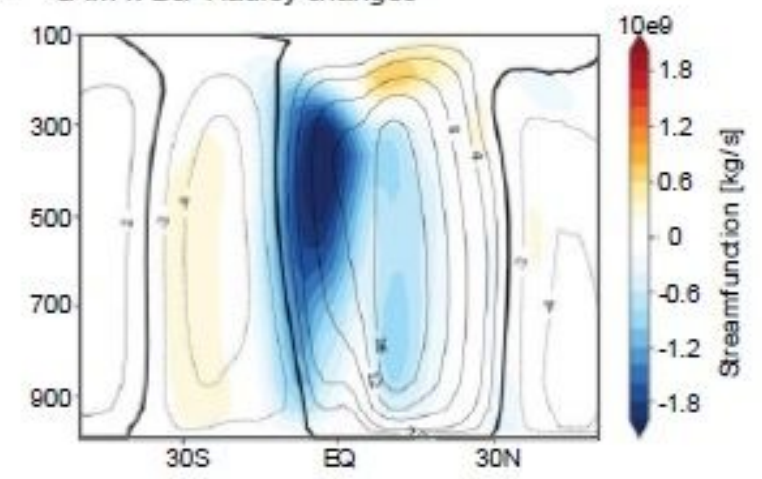

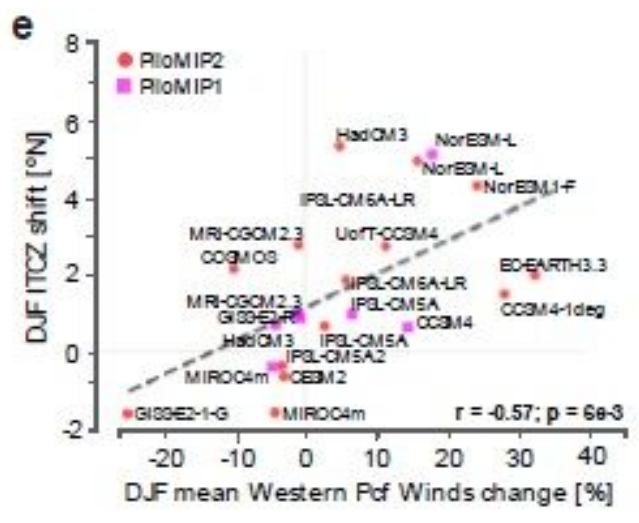

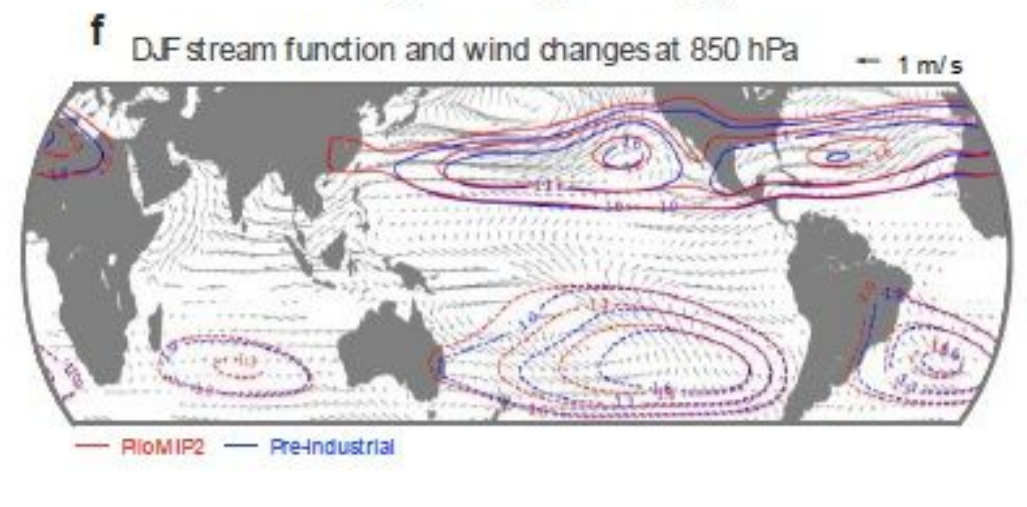

\section{Figure 5}

Energetics constraints for the ITCZ position. a) DJF precipitation change in the PlioMIP2 models (mPWP minus pre-industrial). Stippling indicates where the change is significant at the $95 \%$ level. b) multi-model mean change zonally averaged SST for the PlioMIP1 (magenta) and PLioMIP2 (red). Banding indicates standard deviation range. c) Changes in DJF atmospheric energy flux, computed as the residual between the total top-of-the-atmosphere and surface energy fluxes, in the CAM4 experiments forced with PlioMIP1 and 2 climatological SST and sea-ice (see Methods). Banding indicates standard deviation range of a 5member ensemble. d) Changes in the meridional streamfunction in the CAM4 experiment forced with PlioMIP2 SST and sea-ice (see Methods). y-axis: Pressure [mb]. Contours indicate pre-industrial streamfunction (zero contour in bold). Colours indicate change (mPWP minus pre-industrial) e) Intermodel relationship between changes in the intensity of the zonal western Pacific trades and ITCZ shift during austral summer. $\mathrm{f})$ Changes in global low-level $(850 \mathrm{hPa})$ winds and stream function in the PlioMIP2 models. Wind changes are only plotted where there is a significant change at the $95 \%$ level. 
Note: The designations employed and the presentation of the material on this map do not imply the expression of any opinion whatsoever on the part of Research Square concerning the legal status of any country, territory, city or area or of its authorities, or concerning the delimitation of its frontiers or boundaries. This map has been provided by the authors.

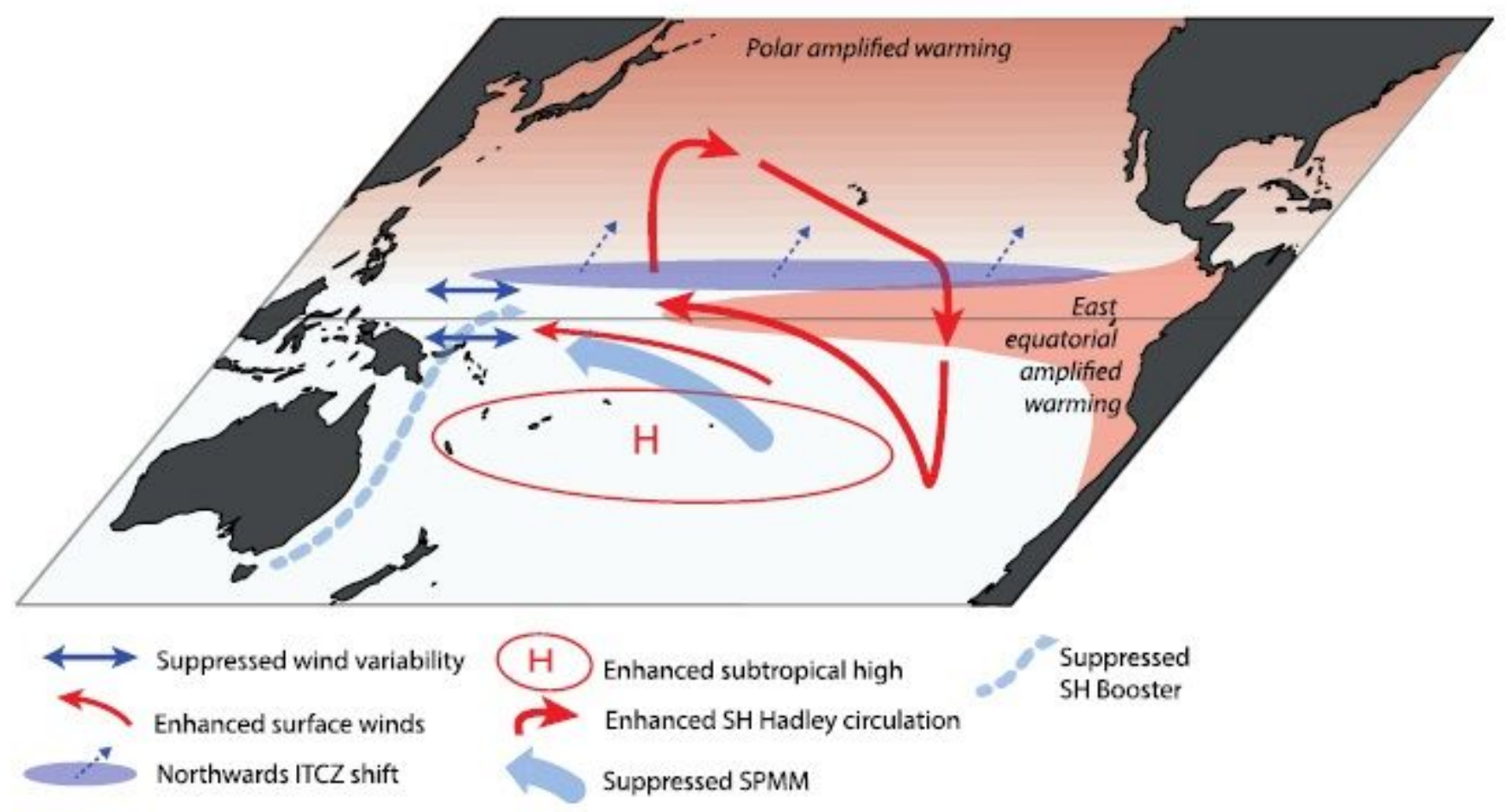

Figure 6

Schematic of the drivers of suppressed ENSO activity in the MPWP. A northward ITCZ shift reduces the probability of occurrence of deep convection in the central-eastern Pacific. Energetic constrains for the ITCZ position indicates that higher rates of warming in Northern Hemisphere drive a northward ITCZ shift and intensified enhanced Southern Hemisphere Hadley circulation. These changes are also associated with enhanced subtropical high and intensified western Pacific trades. Enhanced trade windssuppress wind variability in the western Pacific, which are important for El Niño initiation. An intensified subtropical high is thought to impede zonal pressure anomalies across the tropical South Pacific and, thus, suppress the activity of the South Pacific Meridional Mode (SPMM) and Southern Hemisphere Booster that are important for the development of strong El Niño events. Note: The designations employed and the presentation of the material on this map do not imply the expression of any opinion whatsoever on the part of Research Square concerning the legal status of any country, territory, city or area or of its authorities, or concerning the delimitation of its frontiers or boundaries. This map has been provided by the authors.

\section{Supplementary Files}


This is a list of supplementary files associated with this preprint. Click to download.

- PontesetalnewSIfinal.pdf 